Portland State University

PDXScholar

6-6-1978

\title{
A Descriptive Study of Social Service Needs and Demographic Characteristics of Selected Emergency Room Patients
}

Anne K. Parker

Portland State University

Follow this and additional works at: https://pdxscholar.library.pdx.edu/open_access_etds

Part of the Emergency Medicine Commons, and the Social Work Commons Let us know how access to this document benefits you.

\section{Recommended Citation}

Parker, Anne K., "A Descriptive Study of Social Service Needs and Demographic Characteristics of Selected Emergency Room Patients" (1978). Dissertations and Theses. Paper 2777.

https://doi.org/10.15760/etd.2773

This Thesis is brought to you for free and open access. It has been accepted for inclusion in Dissertations and Theses by an authorized administrator of PDXScholar. Please contact us if we can make this document more accessible: pdxscholar@pdx.edu. 
A DESCRIPTIVE STUDY OF SOCIAL SERVICE NEEDS AND DEMDGRAPHIC CHARACTERISTICS OF SELECTED

EMERGENCY ROOM PATIENTS

by

ANNE K. PARKER

A report submitted by Anne $K$. Parker in partial fulfillment of the requirements for the degree of

\author{
MASTER \\ of \\ SOCIAL WORK
}

Portland State University 
TO THE OFFICE OF GRADUATE STUDIES AND RESEARCH:

The advisor to Anne K. Parker approves the research practicum presented June 6, 1978.

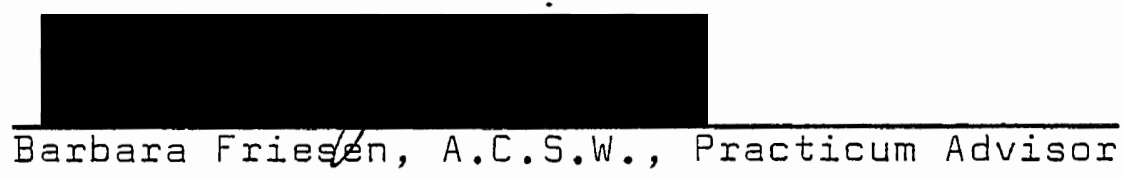

APPROVED :

Bernard Ross, Dean, School of Social Work 


\section{ACKNOWLEDGEMENTS}

I'd first like to thank Joe, whose loving patience and understanding have made this project much easier. I'd also like to thank Barbara Friesen, Nancy Koroloff and Susan Hines for their technical assistance and their encouragement throughout the year.

A special thanks goes to Phil DiMeco for his unflagging énthusiasm and assistance, and to the staff of Providence Medical Center's emergency room, whose help and cooperation made this study possible. 


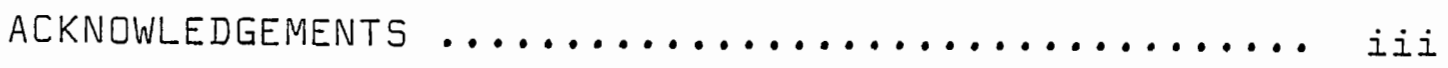
LIST OF TABLES ....................... viii

\section{CHAPTER}

I INTRODUCTION $\ldots \ldots \ldots \ldots \ldots \ldots \ldots \ldots \ldots \ldots$

Background $\ldots \ldots \ldots \ldots \ldots \ldots \ldots \ldots \ldots \ldots$

Purpose $\ldots \ldots \ldots \ldots \ldots \ldots \ldots \ldots \ldots \ldots$

Problem Statement ............... 3

Definition .................... 3

I I THEORETICAL FRAMEWORK $\ldots \ldots \ldots \ldots \ldots \ldots \ldots$

Introduction $\ldots \ldots \ldots \ldots \ldots \ldots \ldots \ldots \ldots$

Hierarchy of Needs ...............6 6

Nutritional Model ............... 7

Crisis Theory ................ 7

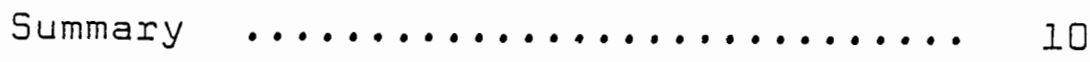

II REVIEW OF THE LITERATURE -

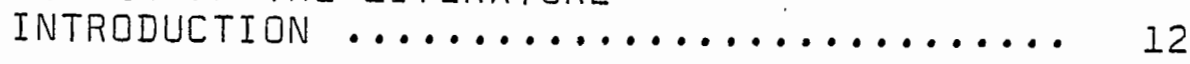

TYPES OF PROGRAMS AVAILABLE ........... I4

Background ................... 14

Social Service Programs ........... 15

Psychiatric and Crisis Counseling

Programs ..................... 16

Summary $\ldots \ldots \ldots \ldots \ldots . \ldots . \ldots . . \ldots 23$

CHARACTERISTICS OF PATIENTS .......... 23

Introduction $\ldots \ldots \ldots \ldots \ldots \ldots . \ldots . \ldots 23$ 
PAGE

Major Studies Reviewed ............. 24

Demographic Characteristics ........ 27

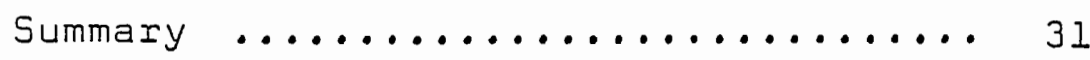

IV METHODOLOGY - OVERVIEW ............. 33

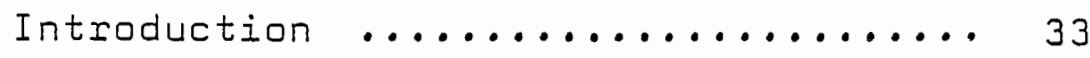

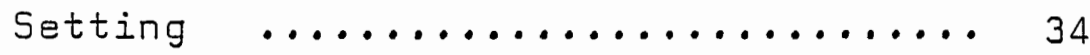

SAMPLING PRDCEDURE .................. 34

The Sample ....................... 34

Exclusions From the Population ...... 36

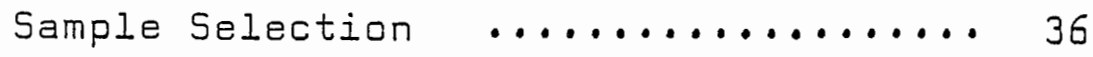

Exclusions From the Sample ........ 37

Adherence to the Sampling Schedule ... 37

INSTRUMENTS $\ldots \ldots \ldots \ldots . \ldots \ldots . . \ldots \ldots$

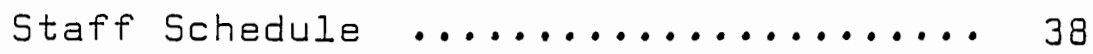

Patient and Parent Schedules ........ 41

Rationale for Use of Schedules ...... 44

Pre-Test .........................4 45

LIMITATIONS OF THE STUDY ............. 45

Sample ...........................45

Patient and Parent Schedules ......... 46

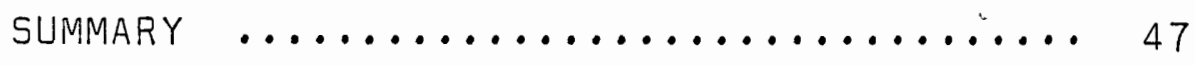

V ANALYSIS OF DATA - STAFF SCHEDULE ....... 48

General Comments ..................4 48

Day and shift ....................4 48 
Arrival Time in the Emergency Room .... 48

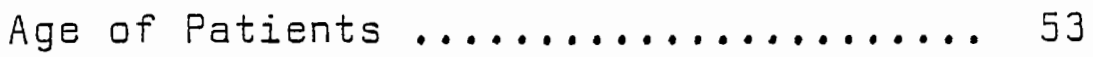

Sex of Patients .......................53

Patients' Chief Complaint: Staff's

Preliminary Diagnosis .............

Presence of Self-Destructive

Behavior

Referral to a Social Worker ......... 55

Reason for Referral to a Social Worker. 57

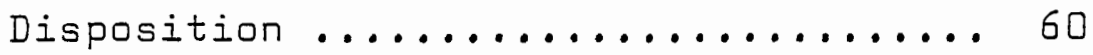

Addresses of Patients ..............66 60

Marital status ...................66

Employment status .................66

Insurance Coverage ................667

PATIENT AND PARENT SCHEDULES .......... 71

General Comments ...................71

satisfaction .......................71

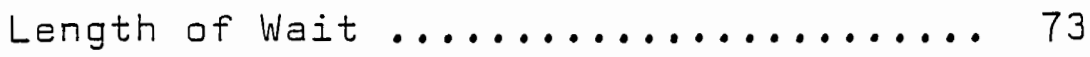

Who Accompanied the Patient to the

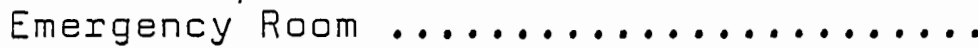

How Many Persons Went to the

Emergency Room With the Patient ....... 76

Services Respondents Wanted Help

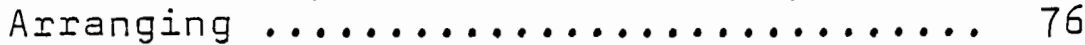

Types of Problems Respondents

Wanted Help With .................. 76

Sex of Respondent who Wanted to

Talk With a Social Worker ........... 78 
Who Wanted Services Compared to Who Would Have Been Referred

Regular Doctor or Clinic ..........

Who Completed Children's

Schedules

Sex of Respondent

Respondent's Level of Formal Education

Marital Status of Respondents ....... 86

Number of Persons Living in the Household '................... 86

Number of Times Patient Has Moved ... 89

VI CONCLUSIONS AND RECOMMENDATIONS $\ldots \ldots . . .99$ INTRODUCTION

MAJOR FINDINGS $\ldots \ldots \ldots \ldots \ldots \ldots \ldots \ldots$

Need for Social Services ........... 93

When Patients Were Admitted ........ 94

Patients' Emergency Room

Experience .................... 95

Demographic Characteristics of

Patients

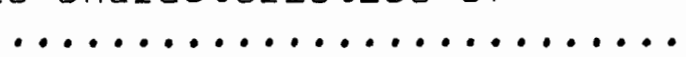

CONCLUSIONS $\ldots \ldots \ldots \ldots \ldots \ldots \ldots \ldots . \ldots \ldots$

RECOMMENDATIONS $\ldots \ldots \ldots \ldots \ldots \ldots \ldots \ldots$

RECOMMENDATIONS FOR FURTHER STUDY $\ldots \ldots \ldots 102$

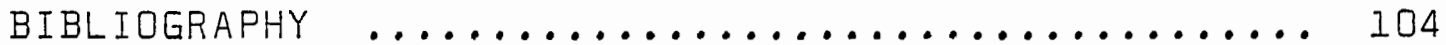

APPENDIX A - SCHEDULES AND COVER LETTERS ........ 109 APPENDIX B - MAP OF CATCHMENT AREAS .......... 124 


\section{LIST OF TABLES}

TABLE

PAGE

I Distribution of Total Sample by Shift .....

I Distribution of Patients Who Would

Have Been Referred

II Arrival Time in Emergency Room

Night Shift

IV Arrival Time In Emergency Room Day

Shif:t

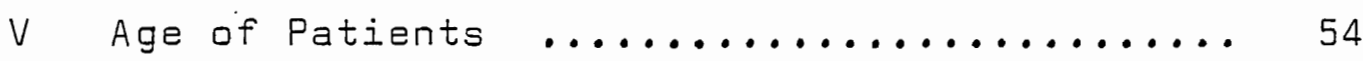

VI Presence of Self-Destructive Behavior ..... 56

VII Services for Which Patients Would Have

Been Referred

VII Types of Mental Health Problems For Which

Patients Would Have Been Referred ......... 59

IX Disposition From Emergency Room ...........6. 6 I

$x$ Distribution of Home Addresses ............ 62

XI Marital Status of Total Sample ............64

XI Marital Status of Patients Over 18 ........ 65

XII Employment Status of Patient (or parent)

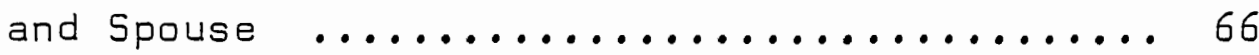

XIV Whether Patient/Parent and/or Spouse

(if any) are Employed ..................668

XV Type of Insurance Coverage ............... 70

XVI Satisfaction of Respondent With Treatment

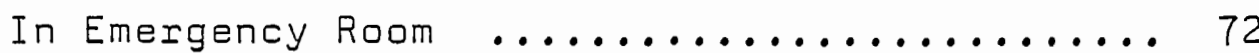


TABLE

PAGE

XVII Length of Time Waited Before Being

Seen by a Doctor ....................... 74

XVIII Who Accompanied Patient to Emergency

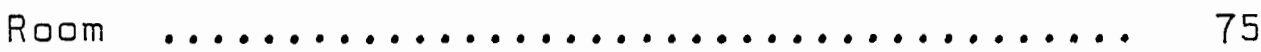

XIX What Respondents Wanted Help Arranging .... 77

$X X$ Types of Problems With Which Respondents

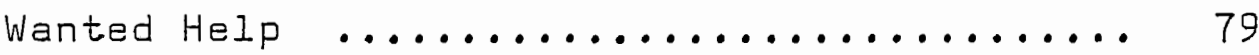

XXI Desire To Talk With A Social Worker by Sex

of Respondent $\ldots \ldots \ldots \ldots \ldots \ldots \ldots \ldots \ldots \ldots \ldots$

XXII Desire to Talk With a Social Worker

$a \& b$

by Whether Would Have Been Referred

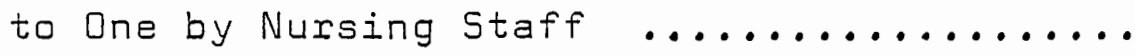

XXII Services Wanted by Respondents who

Would Not Have Been Referred to a Social

Worker

XXIV Years of Formal Education Completed by

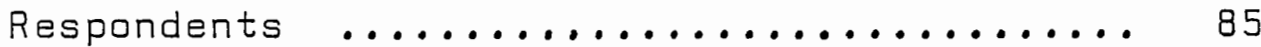

XXV Marital Status of Respondents ............ 87

XXVI Number of People Living With Respondent .... 88

XXVII Number of Times Patient Has Moved in

Previous Two Years ...................... 90 


\section{CHAPTER I}

\section{INTRODUCTION}

\section{Background}

In the Spring of 1977, Phil DiMeco, social worker assigned to Providence Medical Center's emergency room, told the author that the hospital was considering expanding their social work program in the emergency room. He said that the emergency room staff would be interested in a study which could help explore whether additional social work coverage was needed, and, if so, the hours it was most needed. At that time, a social worker was either on duty in the emergency room or on call in the hospital's Social Service Department from 8:00 a.m. to 11:00 p.m., Monday through Friday, and from 6:00 p.m. to 11:00 p.m. Saturday and Sunday.

The author met several times with various emergency room personnel in order to gain a better understanding of: (1) the emergency room's social service program, and how it interfaced with other emergency room services; (2) what information would be helpful to the emergency room staff; (3) how a study could be conducted with the least possible disruption of emergency room routines and services; and (4) what difficulties were likely to be encountered in such a study and how they might be overcome. 
A schedule and the process for completing it were designed with the active participation of the emergency room staff. This ensured that the schedule and its completion process would be as compatible as possible with usual emergency room records and procedures. This cooperative approach also ensured that the study would include as much as possible of the information the emergency room staff wished to collect.

The staff's technical assistance in making the data gathering process as easy and non-disruptive of emergency room procedures as possible, plus their interest in the outcome of the study, resulted in a high level of cooperation from the emergency room staff.

The initial proposal was for a study of the demographic characteristics and social service needs of patients admitted to the emergency room during the hours a social worker was not available. Thus, the hours considered were 1l:00 p.m. to 8:00 a.m., seven days a week, and 8:00 a.m. to 6:00 p.m., Saturday and Sunday. A decision was made to have the hours studied coincide with those of the two nursing shifts on duty during most of the hours a social worker was not available. This reduced the total number of staff persons who needed to participate and made the data collection process easier. As a result of this 
decision, patients who were admitted to the emergency room from 1l:00 p.m. to 7:00 a.m., seven nights a week, and from 7:00 a.m. to 3:00 p.m. Saturday and Sunday, became the basis for this study.

\section{Purpose}

The purpose of this study is to gain information about the social service needs and demographic characteristics of patients admitted to Providence Hospital's emergency room during the hours a social worker is not available. The emergency room staff requested the information in order to utilize it in planning emergency room services.

\section{Problem Statement}

The problem was to investigate and describe demographic characteristics and social service needs of patients admitted to Providence Medical Center's emergency room at night (Il:00 p.m. to 7:00 a.m.) and during weekend day shifts $(7: 00$ a.m. to $3: 00 \mathrm{p} \cdot \mathrm{m}$.$) .$

\section{Definition}

Social services, as used in this report, refer to the assistance with immediate concrete and emotional needs traditionally provided by social workers. This includes helping people obtain needed services through community 
resources, undertaking psychosocial evaluations of patients whose needs are unclear, and providing crisis intervention for those patients and families who are in serious emotional distress. 


\section{CHAPTER I I}

THEORETICAL FRAMEWORK

\section{Introduction}

Many of the services traditionally provided by social workers, such as admission and discharge planning, crisis intervention, and help with practical arrangements, (for instance, transportation, emergency food and/or housing, follow-up medical care, and child care during a parent's illness) can provide much needed assistance to emergency room patients (Bergman, 1976; Strinsky, 1970; Grumet and Trachtman, 1976).

Some patients admitted to emergency rooms do not need anything other than the medical care for which they came. Those patients who do need additional assistance can be divided into four very broad categories. Dne group consists of those patients who need help in meeting some basic needs or in meeting special needs that result from their illness or injury. These might include; people needing housing; nursing home placement; or, home health care for an injury or illness.

A second group of patients and/or their families have a large emotional component to the problem which brought them to the emergency room--their illness or injury may either 
be a result of, or may cause, serious anxiety and emotional upset. Included in this group would be those people whose illness or injury is self-induced, psychosomatic, without physiological basis, was caused by a parent or spouse, or is of such a nature, subjectively or objectively, that it causes great anxiety and grief.

A third group of patients in the emergency room, who need services beyond treatment of the immediate medical problem for which they were admitted, consists of patients who are struggling with an emotional or family problem unrelated to the medical condition for which they came.

A fourth category of patients needing services are those who arrive in the emergency room with no medical complaints, but who are asking for help with personal or family problems.

Intervention with the group of patients needing concrete services will be looked at in terms of Maslow's hierarchy of needs (Maslow, 1948) and Caplan's Nutritional Model (Caplan, 1974). Crisis theory will be used as a framework for understanding the needs of, and intervention with, patients in the emergency room who are seriously upset and anxious.

Hierarchy of Needs

Maslow (1948) states that people's needs are arranged in a hierarchy, with physiological and safety needs at the 
lower end, and needs for self actualization at the top. He states that the lower the need, the more necessary it is for survival. Also, he says that those needs which are on a lower level are subjectively more urgent, and must be met before needs higher up on the scale can be satisfied. For example, a person's need for adequate food, shelter, and/or necessary medical care must be met before he or she can meet emotional needs.

Nutritional Model

Caplan expresses a related idea in what he calls his Nutritional Model (1974). He says that lack of basic physical, psychosocial and/or sociocultural supplies will make a person more susceptible to mental disorder. He states that people need, these mental health nutrients in order to develop healthy personalities just as they need chemical nutrients to develop healthy bodies. Caplan sees efforts to assure that people have access to those things they need as primary prevention of mental disorder.

Thus, concrete, practical services provided to people who are dealing with the stress of physical illness or injury can be considered primary prevention.

\section{Crisis Theory}

Many emergency room patients who are very upset and anxious over family or personal problems, or about their 
illness or injury, are in a state of crisis. Gerald Caplan describes crisis as a state of disequilibrium in which a person is faced with an important problem which he/she is not able to resolve with his/her usual coping methods in the usual amount of time. He states that an essential factor in the occurrence of a crisis is an "imbalance between the difficulty and importance of the problem and the resources immediately available to deal with it" (Caplan, 1964:39).

According to Caplan, people normally exist in a state of balance between their basic physical, psychological, and social needs and their ability to meet these needs. During a state of crisis, this equilibrium is upset. Resolution of the crisis leads to a reestablishment of the previous balance or the establishment of a new one.

Caplan identifies four stages during a crisis period (Caplan, 1964). First, a stressful event occurs. The increased tension results in the person using his/her usual methods of coping to solve the problem. In the second stage, the person experiences a further rise in tension and psychological discomfort as his/her usual coping mechanisms fail to resolve the situation. During this state, the person often feels helpless and experiences some disorganization which results in decreased effectiveness. In the 
third stage, the person tries emergency problem solving methods, making use of both internal and external resources. During this stage, when the person feels overwhelmed by the problem, he/she is more open than usual to intervention. If the problem is resolved during this stage, the fourth stage is asymptomatic. If not, during stage four, the person may experience major disorganization, which can become chronic (Darbonne, 1967; Aguilera and Messick, 1978):

A crisis is time limited, with some authors agreeing that about 6 weeks is the upper limit (Caplan, 1964; Rapaport, 1965).

Stressful events leading to a crisis are often divided into two types. The first is those events which are unanticipated, which occur without warning. Loss of an arm through an accident would be an example of this type of stressful event. The second group consists of stresses which normally and predictably occur during a person's life time, such as marriage, moving, and death of a grandparent. Often, a crisis is triggered by the addition of one new stress to a situation which had prevsiously been uncomfortable but tolerable (Brockopp, 1973). In order for the stressful event to precipitate a crisis, the person must see it as either a threat to or a loss of important physical and/or emotional/social resources, or as a challenge of increased satisfaction but at a higher cost (Caplan, 1964). 
Parad and Caplan (1965) and Rapaport (1965) state that a crisis can bring to the surface an old problem which is symbolically related to the new, precipitating stress. The way in which the ald conflict was dealt with will influence the way the person handles the present problem. However, the new crisis also is an opportunity for the person to find a healthy resolution of the old conflict as well as the present one (Parad et al, 1965).

The healthy resolution of a crisis not only has immediate positive benefits for the person, but also better equips him or her to successfully resolve future problems. On the other hand, if the crisis is handled by the development of maladaptive behaviors, the person is less likely to be able to successfully resolve future crises (Caplan, 1964; Bloom, 1965; Caplan, 1961; Parad and Caplan, 1965; Aguilera and Messick, 1978). The way in which the person resolves the crisis will also change to some extent the significant relationships in his or her life (Caplan, $1964)$.

Summary

Some emergency room patients are in need of concrete services. Providing them with these services can increase the likelihood that they will function in a mentally healthy way. 
Other emergency room patients are in a state of crisis. A person experiences a crisis when he or she is unable to resolve a problem with his/her usual means of doing so. While in a crisis state, a person feels upset and helpless, and is more open than usual to help from other people. The way in which the person resolves the crisis, either maladaptively or successfully, will influence his/her present level of functioning and his or her ability to successfully resolve future crises. 


\section{CHAPTER III}

\section{REVIEW OF THE LITERATURE}

INTRODUCTION

Almost all of the literature in the area of social services available in emergency rooms deal specifically with psychiatric emergency programs providing evaluations of and/or crisis intervention with persons described as psychiatric patients. The term "psychiatric" is rarely defined, and when it is, there is a vast difference in the range and kinds of problems which are included by different programs. In its broadest sense, the term "psychiatric emergency" seems to include the following: acute self-destructive behavior, grossly inappropriate behavior (such as psychosis or an over-reaction to an event, illness or injury), medical complaints caused by anxiety with no physical basis, psychosomatic illness, chronic alcohol or drug abuse, child or spouse abuse, and direct requests for help with personal or family problems (with or without any medical complaints).

However, the psychiatric emergency programs reviewed do not seem to include two groups of people who, in addition to psychiatric patients, are helped in the more inclusive social service programs. The first group consists of those patients needing help dealing with the emotional and prac- 
tical aspects of an illness or injury which is not a result of a psychosomatic process, acute self-destructive behavior, or substance abuse. The second group of patients assisted in social service programs but not in psychiatric emergency programs are those patients who are not labeled as "psychiatric", but need help obtaining community resources (such as emergency food and/or housing, follow-up medical care and nursing home placement).

Almost all of the programs discussed in the literature are described as "psychiatric emergency" or "crisis counseling/crisis intervention" services. This author will use whatever term appears in the literature; whenever the information is available, the actual service(s) provided and/or types of problems dealt with by the various programs will be described. Use of the same term for two programs will not necessarily mean that the two programs provide the same services to the same patients. The term "social service" will be used to designate programs known to serve the two groups of patients described above in addition to assisting patients generally considered to have psychiatric problems. This chapter will be divided into two sections. The first section will describe some of the social service and mental health programs being offered in emergency rooms. As the purpose is to provide an introduction to the wide variety of such programs, the review is not intended to be 
all inclusive. The small number of social service, and large number of psychiatric and crisis intervention programs, reflects what is available in the literature.

The second section of this chapter will review selected studies of the characteristics of patients seen in psychiatric services within general hospital emergency rooms. No literature was available on characteristics of patients assisted by social service programs in emergency rooms.

\section{TYPES OF PROGRAMS AVAILABLE}

\section{Background}

Qver the years, there has been a steady increase in the use of hospital emergency rooms (Shortlife, 1958; Bartolucci and Drayer, 1973; D'Reagan, 1965; Atkins, 1967; Chafetz et al, 1966). Some of the reasons postulated in the literature for this increase are: the convenience of emergency rooms, which are always open and don't require an appointment; the inaccessibility of private physicians for many lower class persons; and that emergency room services may cost a poor person less than a private physician's fees if the hospital charges on a sliding scale.

Reports of the percentage of emergency room patients who have psychiatric problems range from $4 \%$ (Amdur and Tudor, 1975a) to $28 \%$ (Nigro, 1970). Some of these differences can be attributed to differences in the research designs, the 
definitions of psychiatric problems, the population served by the hospital, the availability in the community of alternative services, and the training of the person(s) identifying patients with psychiatric problems.

In order to meet the needs of this group of emergency room patients, some hospitals have established a psychiatric and/or social service program. All but a few of these are in teaching hospitals which have a psychiatric department.

\section{Social Service Programs}

\section{A. Sinai Hospital}

From 8:30 a.m. to 10:00 p.m., Monday though Friday, Sinai Hospital in Baltimore has a social worker on duty in the emergency room (Strinsky, 1970). There is no night or weekend coverage. The social worker provides a broad range of services to patients and their families, including planning for discharge (or admission to the hospital); help with practical arrangements and use of community resources to meet needs; crisis intervention; and assessing and helping the patient deal with his/her emotional reaction to, and fears about, his/her illness or injury.

\section{B. Strong Memorial Hospital}

Beginning in 1972, Strong Memorial Hospital in Rochester, New York, hired four social workers to be available in the emergency room from 8:00 a.m. to 10:00 p.m., 
Monday through Friday, noon to 8:00 p.m. on weekends, and on call by phone and to come in during all other hours (Bergman, 1976). These social workers provide advocacy, crisis intervention, supportive therapy, discharge planning, referral, coordination of services, and work with doctors and patients in suspected child abuse cases. Bergman does not state whether the social workers replace, work with, or are considered a completely separate service from the psychiatric residents mentioned by Atkins (1967).

\section{Psychiatric and Crisis Counseling Programs}

\section{A. Bronx Municipal Hospital}

Probably the first program which attempted to provide comprehensive and immediate psychiatric services to patients admitted to the emergency room was at the Bronx Municipal Hospital of the Albert Einstein Medical Center (Blane et al., 1967). First and second year psychiatric residents, present in the emergency room, see all patients who are referred by the admitting physician. Though it is not entirely clear, the primary purpose of the service apparently is to screen patients and refer them to the most appropriate intra-hospital service.

In addition, a psychiatric walk-in clinic is open in the daytime, Monday through Friday. Many referrals to the walk-in clinic come from the emergency room. A social worker 
is on call to the walk-in clinic at all times; however, it is not clear whether this also applies to the emergency room.

\section{B. City Hospital}

City Hospital in Queens, New York (Bellak, 1964; Blane et al., 1967) operates a program similar to that of Bronx Municipal Hospital described above. A psychiatric resident or a staff psychiatrist (the reports are unclear which) screens all patients admitted to the emergency room at night. In addition, social workers are on duty two nights a week. Persons with psychiatric problems are then referred to an appropriate resource within the hospital or in the community. The nature and extent of the daytime psychiatric coverage in the emergency room is not specified, nor is it clear whether social workers are available during daytime hours.

In addition to the emergency room coverage, City Hospital operates a 24-hour, seven-day-a-week, psychiatric walkin clinic called the Trouble Shooting Clinic. Staffed by psychiatric residents, psychiatrists, social workers, and psychologists, the Clinic provides crisis intervention, brief treatment ( $3-5$ sessions), and referral services for longer-term treatment. 


\section{Massachusetts General Hospital}

Massachusetts General Hospital developed a psychiatric program within the emergency room staffed by psychiatrists, psychiatric residents, psychiatric social workers, a social work assistant, and research and clerical staff (Blane et al, 1967). A psychiatric resident is always on duty; social workers are present until 9:00 p.m. and one is, on call on weekends.

The emergency room patients with psychiatric or emotional difficulties are referred to a psychiatric team by the admitting medical doctor. The social worker talks with both the patient and with anyone who came with him/her, gathering a social history and assessing the patient's problem and resources. The psychiatric resident also interviews the patient, often while the social worker is talking with the person(s), if any, who accompanied him/her to the emergency room. The resident and the social worker then develop both a short-term and a long-term plan for the patient, often involving community resources as well as in-hospital facilities. Each morning, a staff psychiatrist reviews the records of all patients seen in the previous 24 hours, evaluating and, if necessary, modifying treatment plans.

\section{University Hospital}

The University Hospital at Saskatoon, Saskatchewan, has a psychiatrist, psychiatric resident, and a 
social worker on duty in the emergency room from 8:00 a.m. to 5:00 p.m., Monday through Friday, and on Saturday morning (O'Reagan, 1965). During all other hours, a psychiatric resident is on call, with back-up provided by a psychiatrist. The psychiatric staff has the option of seeing emergency room patients for up to 5 return visits; in addition, three beds are available for emergency in-patient care.

\section{E. Colorado General Hospital}

The University of Colorado Medical Center operates a psychiatric service in the emergency room of Colorado General Hospital (Hersrud et al, 1977). Teams of psychiatric residents, social workers, and psychiatric nurses provide 24-hour service to walk-in patients, offer consultation to the emergency room staff, and evaluate admissions to Colorado Psychiatric Hospital.

\section{F. Grace-New Haven Community Hospital}

Second and third year psychiatric residents at Grace-New Haven Community Hospital are on 24-hour call to consult with the emergency room admitting physician (Trier and Levy, 1969; Coleman and Errera, 1963; Blane et al, 1967). Psychiatric residents and social workers attend daily clinic conferences where difficult cases are discussed. However, 
it is unclear from the literature whether the social workers are available to the emergency room.

\section{G. San Mateo County General Hospital}

Residents utilize an intake screening device to increase the appropriateness of the disposition of psychiatric patients in San Mateo County General Hospital's emergency room (Trier and Levy, 1969). There is no description of the screening device, nor is it clear whether the residents are psychiatric residents. The service seems to be limited to intake screening, and no other staff members or other services (such as social work or psychological services) are mentioned (Blane et al, 1967).

\section{H. St. Vincent's Hospital}

At St. Vincent's Hospital in New York, psychiatric residents backed up by psychiatrists offer unspecified services in the emergency room, with referrals given when additional treatment is needed (Blane et al, 1967). It is not stated whether additional mental health professionals are available.

I. University Hospitals

In Cleveland's University Hospitals, on-call psychiatric residents offer consultation to the emergency room, medical-surgical wards, and outpatient clinics. A 
social worker is involved in initial evaluations of patients. About $50 \%$ of the consultation requests come from the emergency room staff (Blane et al, 1967).

J. Edward J. Meyer Memorial Hospital

In Buffalo, New York, the Edward J. Meyer Memorial Hospital utilizes psychiatric residents, social workers, and psychiatric nurses to provide 24-hour coverage of the emergency room (Hersrud et al, 1977). Treatment is available for both emergency room patients and persons calling on the telephone. In addition, up to four patients can be kept for up to 24 hours in the emergency room area for abservation and evaluation.

\section{K. Valley General Hospital}

In Renton, Washington, Valley General Hospital utilizes well-trained graduate students and community volunteers to provide crisis counseling in the emergency room (Getz, 1975; Getz et al, 1977). Originally on duty from 6:00 p.m. until 2:00 a.m., they are now available from 11:00 a.m. to 2:00 a.m. seven days a week. They provide crisis intervention and referral services to about 100 patients each month who are referred by the emergency room physician and about 120 who call on the telephone. A psychiatrist on call to the emergency room acts as a back-up consultant to the crisis counselor. 


\section{John F. Kennedy Medical Centex}

A staff person specially trained in crisis intervention is on duty in the emergency room during peak hours at the John $F$. Kennedy Medical Center in Edison, New Jersey (Sherber and Russell, 1976). This person, whose professional training is not stated, does crisis counseling with patients and their families, initiates psychiatric evaluations and provides referrals and help obtaining on-going counseling and other needed services. During an unspecified period of time, the crisis counselor saw about $15 \%$ of the patients admitted to the emergency room during the covered hours.

\section{Misercordia Hospital Medical Center}

Misercordia Hospital Medical Center in Bronx, New York, uses registered nurses as crisis interventionists (Hankoff et al, I974). These nurses receive assistance and consultation from the nursing supervisor and from the psychiatric staff on call to the emergency room for consultation. In addition, the nurses doing crisis intervention meet monthly with a consulting psychiatrist.

\section{N. Memorial Hospital}

Backed up by a consulting psychiatrist and psychologist, an internist and a social worker run the small, 
24-hour on-call psychiatric emergency service at Memorial Hospital in North Conway, New Hampshire, (Blane et al, 1967). Located in a rural area, the program originally was designed as a federally-funded demonstration project to provide comprehensive services to people in the area having alcohol problems. However, the community has gradually demanded that the service be available to persons with psychological problems unrelated to alcohol use.

\section{Summary}

Descriptions of a number of different programs providing mental health services in general hospital emergency rooms are available in the literature. These descriptions show a wide range in what services are offered, which profession or professions are providing the services, and the hours they are available.

\section{CHARACTERISTICS OF PATIENTS}

\section{Introduction}

This section of the literature review will focus on demographic characteristics of patients seen in psychiatric emergency services located in the emergency rooms of general hospitals. It will begin with a brief description of the major studies to be cited, then review some of the data found in these studies. 
The author was unable to locate any studies presenting information on the characteristics of patients utilizing broader social service programs in emergency rooms.

\section{Major Studies Reviewed}

The University Hospital in Saskatoon, Saskatchewan, is a 600-bed teaching hospital with psychiatric staff on duty in the emergency room 9:00 a.m. to 5:00 p.m. weekdays, and Saturday mornings (D'Reagan, 1965). A psychiatric resident is on call during all other hours. The sample used by O'Reagan for his study consists of 133 consecutive patients seen by the psychiatric emergency staff beginning January 1 , 1964 .

During 1964-1965, Strong Memorial Hospital, located in Rochester, New York, had a psychiatric resident assigned to the emergency room at all times with a psychiatric social worker also present part of the time (Atkins, 1967). The data which Atkins reports from this hospital is based on 7,684 visits to this emergency psychiatric service during fiscal year 1964-1965. (This was prior to the expansion of the program into a social service program in 1972).

Muller, Chafetz and Blane (1967) compare previously reported data from five psychiatric emergency services with information gathered from the 24 -hour emergency service of Massachusetts General Hospital. Only the data from Massa- 
chusetts General will be reviewed here. In 1965, about 4000 psychiatric cases were seen in the emergency room by the psychiatric staff; due to systematic use of pre-planned return visits, the actual number of patient contacts was around 6500. Muller, Chafetz and Blane report on data gathered from 1,792 consecutive cases, excluding repeat contacts, seen by the emergency room psychiatric service between March and August, 1965.

The 408 visits by 350 patients seen by the psychiatric service in the University of Ottowa's General Hospital emergency room provide the basis of Blais' and Georges' (1969) report. The patients were admitted over a unspecified 8-month period.

Watson (1969) defines patients admitted to London's Kings' College Hospital as having psychiatric problems if (1) they have a deliberately self-induced injury or poisoning, or (2) they are given a psychiatric diagnosis and have no medical or surgical problems. Using this definition, Watson reports on 23 psychiatric visits lout of 848 total emergency room admissions) to Kings' College Hospital during an unspecified period in 1965.

During July and August, 1970, 270 patients were seen by the adolescent and adult psychiatric emergency team in the emergency room of Johns Hopkins Hospital in Baltimore. Data reported by Huffine and Craig (1974) reflects the demographic characteristics of these patients. 
During the first 6 months of 1972, 246 emergency room patients at Wesley Pavillion in Chicago, were either the subject of consultation with the psychiatric service or were admitted to the intensive care unit as a result of an overdose. Amdur and Tudor (1975a) call these their "psychiatric" group. During the same time period, 154 patients were discharged from the emergency room with a primary psychiatric disgnosis, with no psychiatric consultation requested. These patients make up Amdur and Tudor's "medical-psychiatric" group. In addition, they use a random sample of 160 patients admitted to the emergency room during June, 1972, as a comparison group. Amdur and Tudor's study is based on information collected from the emergency room charts of the patients in these three groups.

Tally (1977) reports on patients referred to the psychiatric service in the emergency room of a 500-bed university hospital (formerly a county hospital) in Portland, Oregon. Psychiatric residents are on duty 24 -hours a day, and a psychiatric nurse is available during daytime hours, Monday through Friday. Tally's data is based on the 1,478 patients admitted to the emergency room from January 2, 1976 , through May 31, 1976, who requested psychiatric help or whose diagnosis included psychiatric problems.

With this brief discussion of the samples being used in the various studies, the data they present will now be reviewed. 
Demographic Characteristics

\section{A. $\underline{\text { Sex }}$}

Almost all studies of patients visiting general hospital emergency rooms who are seen by the psychiatric service provide information on the sex of the patient seen. Of the seven studies reviewed which give information on the patients' sex, three report more female than male patients (Blais and Georges, 1969; Huffine and Craig, 1974; Atkins, 1967). Three others report more males than females (Tally, 1977; Watson, 1969; D'Reagan, 1965).

Muller, Chafetz and Blane (1967) state that they found no overall difference in the percentage of males and females. They then further analyzed the data to see if there was a difference within specific subgroups. They report that those patients admitted with medical/psychiatric difficulties had an equal representation of men and women. Persons admitted primarily for alcohol problems were predominantly middle-aged men, whereas the majority of those considered to have primarily psychiatric (rather than alcohol or medical) problems were young females. As the age being considered increased, the women's majority in this group decreased until, by middle age, more men than women were seen.

\section{B. Age}

Although most studies reviewed give information on the age of patients in the sample, the data is not always 
comparable.

Huffine and Craig (1974), Blais and Georges (1969), and Tally (1977) use similar age groupings to report their data. Of their samples, 9-11\% of the patients were under 20 , and $4-6 \%$ were over 59 years old. All three report that more than half of their sample was between 20 and 40 years old. Tally's study shows $41 \%$ of the patients between 20 and $30--t h e$ highest percent reported for any 10-year age range in these three studies.

Atkins (1967) reports $68 \%$ of his sample was between the ages of 20 and 50; Blais and Georges (1969) and Huffine and Craig (1974) both report $72 \%$ of the patients in their sample were in this age range, and Tally's (1977) study reports $77 \%$ of the patients in this group.

Seventy percent of O'Reagan's (1965) sample was between the ages of 20 and 60 .

Muller, Chafetz and Blane (1967) compare the distribution of ages of people using Massachusetts General Hospital's emergency psychiatric service with persons in the community it serves. They report a higher proportion of young people and a lower proportion of old people using the service than would be expected by their representation in the community. In Huffine and Craig's study (1974), the middle range of ages was over-represented and the older range ages were under-represented when compared with their 
proportion in the general population served by the hospital. Overall, the studies report that the majority of patients utilizing the psychiatric emergency services are young adults, with relatively few older (60+) persons being seen.

\section{[. Marital Status}

Of the six studies reviewed which give this information, 5 report a majority of persons in the sample were unmarried--single, separated, divorced, or widowed (Muller et al, 1967; O'Reagan, 1965; Amdur and Tudor, 1975a; Huffine and Craig, 1974; and Blais and Georges, 1969). Atkins (1967) reports the only sample with more married than unmarried persons. The proportion of unmarried persons range from $45 \%$ in Atkins' study to $72 \%$ in O'Reagan's report.

Amdur and Tudor's sample is divided into three groups. The psychiatric group consists of patients for whom a psychiatric consult had been sought plus all patients admitted to intensive care with a diagnosis of overdose. The medicalpsychiatric group includes all patients discharged from the emergency room with a primary psychiatric diagnosis (not including alcoholism) but for whom no psychiatric consultation was requested. The third group is a random sample of patients admitted to the emergency room for any reason.

They state that, although $41 \%$ of the random sample was married, only $38 \%$ of the medical psychiatic group and $27.5 \%$ 
of the psychiatric group were married.

Three studies provide data on marital status which can be compared using three groupings--single, married, and separated, divorced or widowed (Huffine and Craig, 1974; Muller et al, 1967; Blais and Georges, 1969). In two of these studies there are more married persons than either other group; the single category is largest in the third study. Separated, divorced or widowed is the least common group of marital statuses in two reports, with little difference (2\%) between that group and the group of single patients in the third study.

Because the marital status of $25 \%$ of Tally's sample is unknown, the data from that study is not reviewed here.

\section{Arrival Time}

The arrival time of patients using psychiatric services in general emergency rooms are given in four studies. Tally (1977) and Huffine and Craig (1974) both report more patients being admitted in the afternoon than in the morning. In all the studies, more patients were admitted during daytime hours than evening or night shifts. The night shift was consistently the least busy shift. Depending on the study, from $45 \%$ to $75 \%$ of patients seen in the psychiatric emergency service were admitted during the day. During evening hours (till 1l:00 p.m. or midnight), the range is $21 \%$ to $39 \%$; at night, the range varries from $5 \%$ to $22 \%$. 
Amdur and Tudor (1975a), Watson (1969) and Bellak, Prola, Meyer, and Zunkerman (1964) all agree that the total number of patients seen in a psychiatric service in a general hospital emergency room at night is relatively low. They also state that of all patients admitted to an emergency room at night, a higher percentage have psychiatric difficulties than is true of patients admitted during day and evening hours.

Tally's study reports that in absolute numbers and in terms of the percentage of all patients admitted to the emergency room, more psychiatric patients were seen on Tuesday and Friday. This is the only study that indicates the day of the week patients were admitted.

Though there is some variance in the pattern of usage, most patients seen by a psychiatric service of an emergency room are admitted during the day, followed in frequency by evening and then by night admissions.

\section{Summary}

A number of studies report on the demographic characteristics of psychiatric patients. The studies reviewed here are evenly divided in reporting more male or more female patients. Dne study reports that other variables such as diagnosis and age may affect the proportion of males and females. 
The studies reviewed generally report a large number of young adults, with relatively few persons over 60 . The majority of them are unmarried. Most patients arrive in the emergency room during the daytime, with evenings being the second most common time period for admissions, and nights being least common. Several studies state that of all patients admitted to a general hospital emergency room at night, a larger percent have psychiatric problems than is true for patients admitted during day and evening hours. The reader should remember that the studies reviewed do not use a common definition of "psychiatric". Also, no studies were available on characteristics of emergency room patients with social service needs that are broader than are included in studies of psychiatric emergencies. Therefore, the patient characteristics reported by studies reviewed here are only very roughly analogous to the findings of this author's study. 


\section{CHAPTER IV}

METHODOLOGY

OVERVIEW

\section{Introduction}

Providence Hospital's emergency room presently has a social worker available either in the emergency room or on call from the Social Service Department Monday through Friday from 8:00 a.m. to $11: 00$ p.m., and from 6:00 p.m. to 11:00 p.m. Saturday and Sunday. This study was designed to gather information about the characteristics and social service needs of patients admitted to the emergency room during the night and weekend day shifts, when a social worker is not presently available.

After preliminary discussions with staff members of the emergency department at. Providence Medical Center, the researcher selected a random sample of patients seen in Providence's emergency room during selected night shifts (II:00 p.m. to 7:00 a.m.) and weekend day shifts (7:00 a.m. to 3:00 p.m.) in January and February, 1978. A schedule was completed by the staff or the researcher for each patient in the sample. A second schedule was then mailed to patients in the sample 15 years or older, and a third to parents of patients under 15. The only persons not receiving a schedule were those who died in the emergency room and those for 
whom a current address was not available. A second copy was mailed to persons who did not return their schedule within three weeks.

The responses to all schedules were transferred to a coding sheet, then keypunched onto data cards. Data was then analyzed by computer.

Setting

Providence Medical Center is a 483-bed private, nonprofit hospital in N.E. Portland, Oregon. The hospital has a small, short-term psychiatric unit, a residency program for physicians, and a training program for hospital chaplains.

In 1977, 29,599 patients were seen in Providence's emergency room. Since January, 1976, there has been a social worker on duty in the emergency room from 5:00 p.m. to 11:00 p.m. seven days a week. During 1976, 217 patients and families were served by the emergency room social worker. 1977 statistics were unavailable.

\section{SAMPLING PROCEDURE}

\section{The Sample}

Selection of the time period to be sampled was based on the following factors: (1) the researcher wanted as long a sample period as was feasible so as to obtain the most 
reliable information possible; (2) the researcher could not have the schedule to be completed by the emergency room staff ready for use before December 1, 1976; (3) from December 1 through December 31, 1976, Providence's emergency room staff was to participate in an unrelated survey of patients in local hospital emergency rooms; (4) the researcher did not want to ask the emergency room staff to complete schedules for two separate research projects during the same time period because of the possibility of confusion and resulting invalid results for both projects; and (5) in order to meet the deadline for completion of the research project, all patients for the sample had to be selected by February 25, 1978.

Based on these considerations, the eight weeks from January I through February 25, 1978, were chosen as the period to be sampled.

Within this time period, three weeks were selected through the use of a random number table. Each of these weeks was divided into two parts (Sunday-Wednesday and Thursday-Saturday). This was done in order to compare information about patients seen during the night shifts of the first part of the week with those from the second half. Again, using a random number table, two nights were selected from each group for each of the three weeks. This resulted in four randomly-selected nights to be sampled for each of 
the three randomly-selected weeks. In addition, Sunday and Saturday day shifts of the three selected weeks were to be sampled.

Due to the relatively small number of patients who utilize the emergency room during the night, the researcher chose to take a 50 percent sample of patients admitted to the emergency room during that shift (11:00 p.m. to 7:00 a.m.). This made it possible to use a random sample, yet assure an adequate sample.

A 25 percent sample was chosen for the day shifts $(7: 00 \mathrm{a} . \mathrm{m}$. to $3: 00 \mathrm{p} \cdot \mathrm{m}$.$) . Due to higher numbers of patients$ seen on this shift than at night, a 25 percent sample from this shift was sufficiently large to produce reliable data, yet small enough that the research project would be financially feasible.

Exclusions From the Population

The following persons were excluded before a sample was drawn: (1) in-patients at Providence Hospital who were brought down to the emergency department cast room; and (2) persons who arrived at the emergency room for prearranged follow-up care from their personal physician.

\section{Sample Selection}

Once the shifts to be sampled had been chosen, a random number chart was used to select the first patient for each 
shift to be included in the sample. For each of the night shifts, the first or second patient admitted after 11:00 p.m. was randomly selected as the first person in that night's sample. Beginning with that person, every other patient admitted before 7:00 a.m. became part of the sample.

For each of the day shifts, the first, second, third or fourth person admitted after 7:00 a.m. was randomly selected to begin the sample for that day. Starting with that person, every fourth patient admitted to the emergency room before 3:00 p.m. became part of the sample. Persons excluded from the population (see above) were not included in this "counting off" process.

\section{Exclusions from the Sample}

One person was excluded from the sample after the completed schedule was accidently destroyed.

\section{Adherence to the Sampling Schedule}

Once or twice a week, the researcher examined all charts of patients admitted to the emergency room during shifts being sampled in order to list the names (if any) of patients who were to be excluded from the sample population. The researcher then checked the emergency room's register of admissions for each shift against the names and admission times of patients for whom schedules were 
completed. Any divergence from the sampling schedule (persons who should have been included in the sample for whom there were no schedules, or schedules completed for patients who were not in the sample) was then corrected.

\section{INSTRUMENTS}

\section{Staff Schedule}

\section{A.: Description}

\section{After extensive preliminary consultation}

with the emergency room staff and a review of the pertinent literature, a two-part Staff Schedule (See Appendix A) was developed to be completed for every person in the sample. The first section of this schedule asked for information from the patient's emergency room chart, information on self-destructive behavior on the part of the patient, and an assessment by the nursing staff of the patient's social service needs. Section II asked for demographic information from the hospital's admitting form.

\section{B. Completion of Section I}

Section I was completed in one of two ways: (1) due to the high volume of patients admitted to the emergency room on the weekend day shifts, it was not known if the nurses would have time to complete schedules on 
patients. Therefore, the researcher agreed to arrive $1 \frac{1}{2}$ to 2 hours before the shift ended, determine which patients were part of the sample (See Sample Selection), and copy the requested information from the patient's chart onto Section I of the schedule. The nurse who had been most involved with the patient then completed the remaining questions, sometimes conferring first with one or more staff members who had also had contact with the patient; (2) during the night shifts, the charge nurse completed all of Section I, conferring with the other nurse who was on duty as needed regarding presence of selfdestructive behavior by the patient, and whether or not the nursing staff would refer the patient to a social worker if one were available in the emergency room.

\section{c. Completion of Section II}

Completion of Section I I required copying the necessary information directly from the hospital's admission form onto. the schedule. A completed copy of this admission form is attached to the emergency room chart of all new patients. However, if a person has been a patient previously at Providence (and therefore has an admission form on record), the copy attached to his/her emergency room chart is often left incomplete. Though the charts remain in the emergency room for approximately 4 to 
6 weeks, the copy of the admission form is destroyed after 24 hours.

As a result of the above hospital procedure, Section I was completed by one of the following people: (1) by the researcher if a completed admission form was still attached to the patient's chart when she was in the emergency room; (2) by one of the night nurses if the completed form was clipped to the chart, and the nurse both had the time and remembered to copy the information onto the schedule; ( 3 ) by a social worker attached to the emergency room if the completed form was destroyed prior to being copied onto the schedule, and in the numerous situations where the original admitting card had to be abtained from the Medical Records Department because the form attached to the emergency room record was incomplete,

Because the information in this section was copied directly from the admission form, the fact that different people completed this part of the schedule does not effect the reliability of the information.

\section{Validity and Reliability}

Prior to use, this instrument was examined by several professionals from Providence Hospital's Emergency Department, two persons with extensive emergency room 
experience who are not associated with Providence, and a social work instructor. All agreed that the instrument was appropriate for the purpose of the study. No test was made of this instrument's inter-respondent reliability.

Patient and Parent Schedules

\section{A. Patient Schedule}

A second schedule (See Appendix A) was developed to be completed by patients in the sample who were 15 years old or older. This schedule began with questions intended primarily to get the person involved in completing the form, so as to increase the likelihood he or she would return it. These were followed by questions about who had accompanied him/her to the emergency room. Next were two lists from which the person was asked to indicate any problems he/she would have liked to have discussed with a social worker while in the emergency room. (These lists were similar, though not identical, to the lists in the Staff Schedule from which the nurses indicated the services for which they would refer patients to a social worker if one were on duty in the emergency room). These lists were then followed by items requesting demographic information.

\section{B. Parent Schedule}

The third schedule (See Appendix A) designed for this study was a slightly modified version of the patient 
Schedule. This one was developed to be completed by parents or parent substitutes of patients under 15. The major difference between this schedule and the Patient Schedule described above is that the demographic information requested in this version refers to the parent of the patient, rather than the patient.

\section{Completion of Patient and Parent Schedules}

Despite an anticipated lower return rate, it was decided to mail schedules to patients (or parents of patients under 15 ) rather than to ask them to complete the schedules while in the emergency room. This was done for the following reasons: (1) the researcher assumed that many of the patients (or their parents) would be under a relatively high level of emotional stress, and declined to add to it by asking them to complete a schedule while in the emergency room; (2) the researcher was aware that the medical condition of some patients would make it difficult or impossible for them to complete the form while in the emergency room. Most of these persons would, however, be able to complete the schedule at a later date.

The original plan was for all patients in the sample (or their parents), except those known by the researcher to have died, to receive a schedule. This was to be mailed 
1 to 2 weeks after the person's emergency room visit, along with a cover letter (See Appendix A), a stamped, addressed return envelope, and a postcard on which the person could request a summary of the research project's results. Those persons who did not respond within two to three weeks were then to receive another schedule with the cover letter, stamped return envelope, and postcard, plus an additional cover letter (See Appendix A) asking for their cooperation.

Due to occasional difficulty in obtaining current addresses, some people did not receive their first copy of the schedule until as much as a month after their emergency room visit. (The second mailings all went out as scheduled). In addition, four persons in the sample did not receive a schedule because a current address could not be located for them. (One person died in the emergency room and therefore was not included in the mailings).

\section{Validity and Reliability}

Two social workers, a psychiatric nurse with emergency room experience, and the researcher examined and found both of these instruments to be appropriate for the purpose of the study, and to be consistent, item by item, with each other.

These two schedules asked the respondents to answer a number of subjective questions about a particular personal 
event. Therefore, no objective test of reliability was possible. However, the persons who reviewed the schedules for validity also carefully checked items for clarity and readability to help ensure reliability of the instruments.

\section{Rationale for Use of Schedules}

There are advantages and disadvantages to the use of any particular form of research instrument. In this study, the advantages of fixed alternative schedules were considered to outweigh the disadvantages for the following reasons:

(1) the researcher did not have the time to conduct face-toface or telephone interviews, nor the money to hire others to conduct interviews; (2) the researcher could not be present to interview nursing staff about patients admitted to the emergency room at night; (3) it was believed the anonymity of schedules and the ability to complete them in privacy would be conducive to more honest answers to the very personal questions being asked of patients; (4) because the respondent can look at them, schedules make possible longer lists of options to choose from than is feasible in an interview; (5) fixed alternative responses, as compared to open ended questions, decrease the amount of time required on the part of the respondent, therefore increasing the likelihood the schedules would be completed; (6) open ended questions would have been much more difficult and 
time consuming to code for analysis by computer, and would have made comparison of data less reliable or impossible.

\section{Pre-Test}

The Staff Schedule was pre-tested by the nurses warking nights in Providence's emergency room. They completed 6 to 8 schedules on patients seen during two nights. In addition, the researcher conducted a short pre-test of the instrument, transferring information from 4 to 5 patients' charts onto schedules, then having the nurse who had worked most closely with that patient complete the remainder of the form.

No need to modify the instrument was discovered during these pre-tests.

The Patient Schedule and the Parent Schedule were not pre-tested due to lack of an appropriate group with which to conduct such a test.

\section{LIMITATIONS OF THE STUDY}

Sample

One limitation of this study is the fact that the sample was drawn from a two-month period. This may introduce an unknown bias which must be considered when generalizing 
the results to patients admitted to the emergency room during an entire year.

The total number of patients whom the staff indicated would be referred to a social worker was quite small. Therefore, any generalization about characteristics of this group must be made with great caution.

The fact that 42 percent of the persons who received schedules did not return them is another source of possible bias.

\section{Patient and Parent Schedules}

Some of the people who returned their schedules did so within two weeks of their admission to the emergency room; other completed schedules were not received by the researcher until as much as two months after the person's emergency room visit. There is no way to know whether this time variance introduced a bias of some sort into the responses.

These two schedules asked people to answer questions in retrospect about whether they wanted certain services when they were in the emergency room. It is possible that the responses given to these questions would have been different if the schedules had been completed while the patients were still in the emergency room. 
Staff Schedules were completed by the nursing staff for randomly selected patients on randomly selected night and weekend day shifts. Patients in the sample 15 years and older received a Patient Schedule to be completed and returned; parents of children under 15 in the sample received a Parent Schedule. A summary of the data collected from these three schedules will be presented in the next chapter. 


\section{CHAPTER $V$ \\ ANALYSIS OF DATA \\ STAFF SCHEDULE}

General Comments

The total number of completed staff schedules was 104, one for each person in the sample. Some percentages given do not add up to 100 as a result of rounding errors. Unless indicated otherwise, the item being discussed was responded to on all schedules.

Day and Shift

Fifty-eight persons $(56 \%)$ in the sample arrived during the night shift, and 46 persons $(44 \%)$ were admitted on a weekend day shift. Further data pertaining to the day and shift patients were admitted is contained in Table I. Sixteen of the $104(15 \%)$ would have been referred to a social worker if one had been on duty. Of these 16, $9(56 \%)$ were admitted at night and $7(44 \%)$ during the day shift. Table II shows in more detail how these 16 were distributed by shift.

Arrival Time in the Emergency Room

Tables II and IV show the arrival times of persons in the study. Six of the 9 persons who would have been referred to a social worker at night were admitted to the 
TABLE I

DISTRIBUTION OF TOTAL SAMPLE BY SHIFT

Shift Patient Was Admitted Nights - lst
half

Nights - 2nd half 2

Days - Saturday

Days - Sunday

TOTAL
No. of

Patients

23

35

26

20

104
Percent of Patients

$22 \%$

$34 \%$

$25 \%$

$19 \%$

$100 \%$

I Sunday, Monday, Tuesday, Wednesday

2 Thursday, Friday, Saturday 
TABLE I I

DISTRIBUTION OF PATIENTS WHO WOULD HAVE BEEN REFERRED
Shift Patient

Was Admitted

Nights - Ist

$$
\text { half I }
$$

Nights - 2nd

$\operatorname{half}_{2}$ :

Days - Saturday

Days - Sunday

TOTAL
No. of

Patients
Percent of

Patients

$38 \%$

$19 \%$

$12 \%$

$31 \%$

$100 \%$
5

16
3

2

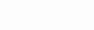

(1)

\footnotetext{
I Sunday, Monday, Tuesday, Wednesday

2 Thursday, Friday, Saturday
} 
TABLE III

\section{ARRIVAL TIME IN EMERGENCY ROOM \\ -NIGHT SHIFT-}

Arrival Time

11:00 p.m. midnight

midnight -

l: $00 \mathrm{a} . \mathrm{m}$.

$1: 00$ a.m. -

$2: 00 \mathrm{a} \cdot \mathrm{m}$.

$2: 00$ a.m. -

$3: 00 \mathrm{a} \cdot \mathrm{m}$.

$3: 00 \mathrm{a} \cdot \mathrm{m} .-$

4:00 a.m.

4:00 a.m. -

$5: 00 \mathrm{a} \cdot \mathrm{m}$.

$5: 00$ a.m. -

$6: 00 \mathrm{a} \cdot \mathrm{m}$.

$6: 00$ a.m. -

7:00 a.m.

TOTAL
Whether Staff would Have Referred Would Would Not $\mathrm{N} \% \mathrm{~N} \%$

1

$I_{1} \quad 1_{2}$

25

0

0

7

15

2

22

6

12

3

33

8

17

I

11

5

10

1

11

2

4

1

II

3

6

0

0

5

10

9

$99 \quad 48$

99

I Due to rounding error, percents do not add up to $100 \%$.

2 Due to coding error, computer lost 1 "would not have been referred" response. 


\section{TABLE IV}

\section{ARRIVAL TIME IN EMERGENCY ROOM -DAY SHIFT -}

Arrival Time

Whether Staff Would Have Referred Would $\mathrm{N} \% \mathrm{~N} \%$

$7: 00 \mathrm{a} \cdot \mathrm{m} \cdot-$

$8: 00 \mathrm{a} . \mathrm{m}$.

0

0

$3_{1}$

8

$8: 00 \mathrm{a} \cdot \mathrm{m} \cdot-$

$9: 00 \mathrm{a} . \mathrm{m}$.

0

0

3

8

$9: 00$ a.m. -

10:00 a.m.

$1 \quad 14 \quad 2$

5

10:00 a.m. -

ll:00 a.m.

2

29

6

15

11:00 a.m. -

12:00 noon

2

29

6

15

12:00 noon -

l:00 p.m.

1

14

7

18

1:00 p.m. -

2:00 p.m.

1

14

7

18

2:00 p.m. -

3:00 p.m.

0

0

6

15

TOTAL

7

100

40

102

1 Due to coding error, computer gained I "would not have been referred" response. Due to rounding error, percents do not add up to $100 \%$. 
emergency room before 3:00 a.m. Of the 7 who would have been referred during day shifts, only one arrived before 10:00 a.m.

\section{Age of Patients}

Table $V$ gives a breakdown of patients' ages by decade. Of the total sample, 32 (30\%) were under 20 and $58(56 \%)$ were under 30 years old.

of the 16 who would have been referred, $8(50 \%)$ were between the ages of 20 and 39 .

Sex of Patients

Men and women were fairly equally represented in the sample, with $59(57 \%)$ men and $45(43 \%)$ women. Half (8) who would have been referred to a social worker were men and half (8) were women.

\section{Patients' Chief Complaint; Staff's Preliminary Disgnosis}

These two questions were eliminated from the study due to difficulties in coding the data.

\section{Presence of Self-Destructive Behavior}

Of the total sample, only 6 persons ( $6 \%$ ) were considered by the nurses to engage in acute or chronic selfdestructive behavior, with an additional $9(9 \%)$ for whom 


\section{TABLE V \\ AGE OF PATIENTS}

Age In Years

Whether Staff Would Have Referred Would Would Not $\mathrm{N} \%$ $\%$

$0-9$

0

017

191

$10-19$

12

13

15

$20-29$

4

25

22

25

$30-39$

4

25

4

4

$40-49$

2

12

6

7

50-59

3

19

10

11

$60-69$

0

0

8

9

$70-79$

0

0

4

4

$80-89$

$I$

6

4

4

TOTAL

16

99

88

98

1 Due to rounding error, percents do not add up to $100 \%$. 
the staff did not have sufficient information to answer this question (See Table VI). Yet, of the 16 patients who would have been referred to a social worker, $3(19 \%)$ were considered to engage in acute or chronic self-destructive behavior, and the staff felt unable to answer this question for $7(44 \%)$. Compared to $85(82 \%)$ of the total sample, the nurses indicated only $5(31 \%)$ of those who would have been referred to a social worker as not appearing to engage in self-destructive behavior. However, the reader must be cautious about generalizing from these figures due to the small number of patients (16) who would have been referred.

Referral to a Social Worker

Of the 104 patients in the sample, the nurses indicated that they would have referred $16(15 \%)$ to a social worker in the emergency room. They would not have referred $87(84 \%)$. This question was not answered on $1(1 \%)$ schedule because the patient had arrived so close to the end of the shift, the nursing staff did not feel they had enough information to complete this section of the schedule. The researcher included this non-response in the "would not trave referred" category, raising the total in that group to $88(85 \%)$. 
TABLE VI

PRESENCE OF SELF-DESTRUCTIVE BEHAVIOR

Type

Whether Staff Would Have Referred $\mathrm{N} \stackrel{\text { Would } \%}{\mathrm{~N}}$

Acute

0

0

1

1

Chronic

3

19

2

2

None

5

31

80

91

Not Known

7

44

2

2

Not Answered

1

6

3

3

TOTAL

16

100

88

99

I Due to rounding error, percents do not add up to $100 \%$. 
Reason for Referral to a Social Worker

For the 16 patients whom they said they would have referred to a social worker, the nurses were asked to check all of the services which they thought the person needed. In order of decreasing frequency, Table VII shows the responses to this question. In addition to those listed in the table, financial help and nursing home placement were each:indicated one time (with a question mark) as services that might be needed.

The total number of services indicated as needed by patients exceeds the number of persons who would have been referred because (as per the instructions) the nurses checked as many services as applied for each patient. In addition to services needed by patients, the nurses were asked to indicate up to three mental health problems for which they would refer the patient to a social worker. This question was intended to further define the problems of patients who would have been referred for counseling. Though the instructions asked the nurses to number the problems from 1 to 3 in order of their importance, most of the nurses simply used up to 3 check marks. Therefore, Table VIII shows only the total number of times an item was indicated as a problem. 
TABLE VII

SERVICES FOR WHICH PATIENTS

WOULD HAVE BEEN REFERRED

Number of

Patients

Service Indicated by Staff

10

Counseling

5

Would refer, but don't know what service(s) are needed

3

Arrange follow-up medical care

2

Other

1

Financial help

1

Immediate temporary housing

1

Transportation now to home or an agency/institution

1

Transportation for medical care at another time

1

Transportation to a social service agency at another time

0

Emergency food

0

Nursing home placement

I More than one response could be indicated for each patient. 
TABLE VIII

TYPES OF MENTAL HEALTH PROBLEMS

FOR WHICH PATIENTS WOULD

HAVE BEEN REFERRED

Number of Patients

$0_{1}$

1

2

4

6

2

0

2

1

0

0

0

1

4

3

0

3
Problem Indicated by Staff

Suicide attempt

Depression (no suicide attempt)

Psychosis

Family problems

Other emotional problems

Difficulty taking care of self

Social isolation

Alcohol problem

Drug problem

Suspected/potential child abuse

Rape/sexual abuse

Non-sexual assault

"Anxious parent" syndrome

Anxiety about how illness/injury may affect his life

Need (by staff) for psycho-social evaluation

Abuse of ER

Other

Up to three responses could be indicated for each patient. 
Disposition

As shown in Table IX, over three-fourths of the patients in the sample were treated and released. Of the 16 whom the staff would have referred to a social worker, 2 were admitted, transportation to Dammasch State Hospital was arranged for $I$, and another was told to come back after 5:00 p.m. when a social worker would be on duty. Of the remaining. 12, all were discharged with no referral for social service assistance.

\section{Addresses of Patients}

Zip codes furnished by patients when admitted were used to indicate the area in which a patient lived, including the 3 which were not still current when the researcher mailed schedules to patients in the sample. The list of zip codes included in Providence Hopital's primary and secondary catchment areas are given in Appendix B. As shown in Table $X$, most of the patients (82) in the sample live in the primary catchment area, with about equal numbers ( 11 and 10 ) from the secondary catchment area and from outside either area. Of those persons who would have been referred to a social worker, $69 \%$ come from the primary catchment area and $19 \%$ are from outside either catchment area. This compares with $81 \%$ and $11 \%$ respectively, of those who would not have been referred. However, this finding 
TABLE IX

DISPOSITION FROM EMERGENCY ROOM

Disposition

Whether Staff Would Have Referred $\mathrm{N} \stackrel{\text { Would }}{\%} \quad \mathrm{~N}^{\text {Would Not }}$

Left $w / 0 T x_{1}$

0

0

2

2

Discharged - referred to $\mathrm{PMC}_{2}$ social service department

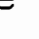

Discharged - no social service referral given

11

69

70

80

Admitted to $\mathrm{PMC}_{2}$

2

12

16

18

Referred for ad-

mission to another

hospital

1

6

0

0

$\mathrm{DOA}_{3}$ or died in

emerggency room

Other

1

6

1

6

0

0

TOTAL

16

99

88

100

\footnotetext{
1 Left, without treatment.

2 Providence Medical Center.

3 Dead on arrival.

4 Due to rounding error, percents do not add up to $100 \%$.
} 


\section{TABLE $X$ \\ DISTRIBUTION OF HOME ADDRESSES}

Location

Primary Catchment

Area

Secondary Catchment

Area

Other Areas

Unknown

TOTAL
11

2

3

0

16
71

9

7

1

88
82

79

11

11

$10 \quad 10$

$1 \quad 1$

$104 \quad 101$

1 Due to rounding error, percents do not add up to $100 \%$. 
must be considered with caution due to the small number of patients in the sample who would have been referred.

Marital Status

Table XI shows the marital status of all patients in the sample. All of the children in the sample are included in the "single" category. Table XII shows the marital status of those persons who are 19 or older. Using these figures so as to avoid an over-representation in the "single" group, of the 77 persons 19 and older, 40 (52\%) were single, divorced, separated, or widowed. Of the 14 persons 19 and older who would have been referred to a social worker, $10(71 \%)$ were not married. These latter figures are based on only 14 patients, and should be interpreted with caution.

\section{Employment Status}

The two questions about employment status of patients and their spouses (or their parents, if the patient was under 19) were asked in order to make a rough estimate of the financial status of patients and their famililies. Table XIII shows the results of a cross-tabulation between these two questions. Assuming that those who stated their occupation as housewife, student, unemployed, retired or disabled were not employed, $44(42 \%)$ of the patients (or 


$$
\begin{gathered}
\text { TABLE。XI } \\
\text { MARITAL STATUS OF TOTAL SAMPLE }
\end{gathered}
$$

Marital Status

Whether Staff Would Have Referred $\mathrm{N} \stackrel{\text { Would }}{\%}$ Would Not $\%$

Single

8

50

42

48

Married

4

25

32

36

Separated

0

0

3

3

Divorced

4

25

7

8

Widowed

0

0

3

3

Unknown

0

0

1

1

TOTAL

16

100

88

99

1 Due to rounding error, percents do not add up to $100 \%$. 
TABLE XII

MARITAL STATUS OF PATIENTS OVER 18

Marital Status

Single

Married

Separated :

Divorced

Widowed

Unknown

TOTAL
Whether Staff Would Have Referred $\mathrm{N}^{\text {Would }} \%$ Would Not $\%$

6

431

17

27

4

29

32

51

0

0

3

5

4

29

7

11

0

0

3

5

0

0

1

2

14

101

63

101

1 Due to rounding error, percents do not add up to $100 \%$. 
Patient -orParent

Housewife would ref. 4 Empl

0
2

0

0

would not ref.

Unemployed would ref. would not ref.

0

$\frac{1}{0}$

9

$\begin{array}{ll}0 & 0 \\ 5 & 1\end{array}$ 1 would not ref.

Disabled would ref. would not ref.

1

$\begin{array}{ll}0 & 0 \\ 2 & 0\end{array}$ $\frac{1}{3}$

Employed would ref. would not ref.

11

17

$\begin{array}{rr}4 & 1 \\ 21 & 3\end{array}$

7

52

Not known would ref. would not ref.

TOTAL

0

0

16
0

$\begin{array}{llll}0 & 0 & 1 & 1\end{array}$

$\begin{array}{llll}0 & 0 & 0 & 0 \\ 0 & 0 & 1 & 1\end{array}$

1 Empl. is employed.

2 Not Empl. is not employed.

$3 \mathrm{~N} / \mathrm{A}$ is not applicable.

4 would Ref. is would have been referred to a social worker by nursing staff.

5 Would Not Ref. is would not have been referred to a social worker by nursing staff. 
their parent) were not employed. Using this same assumption regarding who was unemployed and information given about employment of a spouse, Table XIV shows whether one, both or neither were reported by patients (or their parent) to be employed.

Although no conclusions can be drawn due to the small number of patients involved, in this study $B(50 \%)$ of patients (or their parent) who would have been referred to a social worker were unemployed and either had no spouse or one who was also not employed. This compares to 40 $(38 \%)$ out of the total sample who were unemployed and had no spouse, or whose spouse was not employed.

\section{Insurance Coverage}

As with the questions regarding employment, the items asking about insurance were aimed at obtaining a rough idea of the economic situation of patients and their families. The researcher was given the group numbers of three local low-income insurance programs offered through private insurance companies: Public Welfare's Medicaid, Project Health, and a low-income plan offered by Cascade Health Care. (The researcher was not aware of any additional insurance programs for low-income persons or families). Using this information, plus the stated source of the insurance, each person's insurance coverage was classified as 
TABLE XIV

WHETHER PATIENT/PARENT AND/OR

SPOUSE (IF ANY) ARE EMPLOYED

Number Employed

0

1

2

1 or 2

Unknown if any

TOTAL

16

100

88

99

6

38

41

47

1

6

11

12

1

6

4

4

0

0

1

1

$35_{1}$

7

Whether Staff Would Have Referred Would Would Not

$\%$

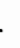


Low income, medicare, other, or unknown type. In addition, there were categories for patients with no insurance, and those for whom it was unknown if they had any insurance. Table XV shows the resultant distribution. Comparing the difference in insurance coverage between those who would have been referred to a social worker and those who would not have been, 4 of the 16 (25\%) who would have been referred had no insurance, compared to 5 of the $88(6 \%)$ who would not have been referred. Also, of those who would have been referred, only 6 of the $16(38 \%)$ were covered with an insurance plan which was not specifically for low-income people, as compared to 46 out of the $88(52 \%)$ who would not have been referred. The reader must remember, though, that there are only 16 patients in the "referred" group.

Combining those persons with no insurance coverage, low-income plans, and Medicare, the figures ( 39 people, or $38 \%$ of the sample) closely resemble those for patients (or their parents) who are not employed and have either no spouse or one who is also not employed (45 people, or $43 \%$ of the sample). 
TABLE XV

TYPE OF INSURANCE COVERAGE

Insurance Coverage

Whether Staff Would Have Referred $\mathrm{N} \stackrel{\text { Would } \%}{\mathrm{~N}^{\text {Would Not }} \%}$

Low Income

4

25

18

20

None

4

25

5

6

Medicare

2

12

12

14

Other

6

38

46

52

Unknown Type

0

0

5

6

Unknown If Any

0

0

2

2

TOTAL

16

100

88

100 


\section{PATIENT AND PARENT SCHEDULES}

\section{General Comments}

Schedules were mailed to 81 of the 85 patients 15 years and older in the sample. Of the remaining 4, 1 had died, and current addresses could not be located for the other 3 .

The remaining 19 patients in the sample were under 15 years old. 'Schedules were sent to the parents' of 18 of these patients. A current address was not available for the remaining patient.

In all, 99 schedules were mailed to patients or their parents. Fifty-eight $(58 \%)$ of these were returned. Fifteen $(83 \%)$ of those mailed to parents were returned, compared to $43(51 \%)$ of those sent to patients. As a result, parents' responses to the items on the schedules are somewhat overrepresented compared to the proportion of children in the sample.

\section{Satisfaction}

Table XVI shows the responses of the first two questions on the schedules. Ninety-three percent of the respondents indicated that they were very satisfied with

Throughout this paper, the term "parent" will include parent, foster parent, and step-parent, unless stated otherwise. 
TABLE XVI

SATISFACTION OF RESPONDENT WITH

TREATMENT IN EMERGENCY ROOM

\begin{tabular}{|c|c|c|c|c|}
\hline \multirow[b]{3}{*}{ Response Checked } & \multicolumn{4}{|c|}{ Item Responded To } \\
\hline & \multicolumn{2}{|c|}{$\begin{array}{l}\text { Quality of } \\
\text { Medical Care }\end{array}$} & \multicolumn{2}{|c|}{$\begin{array}{l}\text { Way Treated } \\
\text { By Staff }\end{array}$} \\
\hline & $\mathrm{N}$ & $\%$ & $\mathrm{~N}$ & $\%$ \\
\hline Not at all satisfied & 1 & 2 & 0 & $0^{1}$ \\
\hline Somewhat satisfied & 2 & 3 & 2 & 3 \\
\hline Mostly satisfied & 6 & 10 & 5 & 9 \\
\hline Very satisfied & 48 & 83 & 49 & 84 \\
\hline No opinion & 0 & 0 & 0 & 0 \\
\hline No response & 1 & 2 & 2 & 3 \\
\hline TOTAL & 58 & 100 & 58 & 99 \\
\hline
\end{tabular}

1 Due to rounding error, percents do not add up to $100 \%$. 
both the quality of medical care they (or their child) received and with the way they (or they and their child) were treated by the hospital staff.

\section{Length of Wait}

Table XVII shows the length of time respondents estimated they had to wait from the time they arrived at the hospital until they (or their child) were seen by a physician. A little more then half $(52 \%)$ waited less than 15 minutes, and $45(78 \%)$ waited 30 minutes or less.

Who Accompanied the Patient to the Emergency Room

of the patients in the sample for whom schedules were returned, most were accompanied to the emergency room by a spouse or person in a similar relationship (17) and/or a parent or step-parent (15). The next most frequently checked response was "no one" (II), followed by "friend(s), neighbor(s), acquaintance(s)"with 9. Six patients had one or more children with them. Table XVIII gives the complete distribution.

Ambulance drivers and taxicab drivers were included in the list of possible responses in order to standardize the responses of persons arriving at the emergency room by ambulance or cab. The only person who checked either of these responses was not accompanied or met at the emergency 
TABLE XVII

LENGTH OF TIME WAITED BEFORE BEING SEEN BY A DOCTOR

Length of Time

Under 15 minutes

15-30 minutes

30 minutes-1 hour

1 - $1 \frac{1}{2}$ hours

Over $1 \frac{1}{2}$ hours

Do Not know

Did Not See a Doctor

No Response Checked

TOTAL
Number of Respondents

$\mathrm{N}$

$\%$

30

$52^{1}$

15

26

4

7

1

2

0

0

5

9

1

2

2

3

58

101

1 Due to rounding error, percents do not add up to $100 \%$. 
TABLE XVIII

WHO ACCOMPANIED PATIENT TO

EMERGENCY ROOM

Who Went With Patient

No one ${ }^{1}$

Husband, Wife, person in similar relationship ${ }^{2}$

Parent.(s), $!^{1}$ step-parent(s) ${ }^{3}$

Foster parent $(s)^{3}$

Child/children ${ }^{2}$

Brother(s), sister(s) ${ }^{3}$

other relatives 1

Friend(s), neighbor(s), acquaintance(s) ${ }^{1}$

Person(s) from church or an agency ${ }^{1}$

Ambulance drivers ${ }^{1}$

Taxicab driver ${ }^{1}$

other ${ }^{1}$

Do Not Know ${ }^{1}$

No Response Checked
Number of Persons

Checking Item ( $N=58)$

$11^{4}$

17

15

1

6

1

3

9

0

1

D

0

0

o

\footnotetext{
1 Listed as possible response on all schedules. 2 Listed as possible response on schedules mailed to patients 15 and over only. 3 Listed as possible response on schedules mailed to parents of patients under 15 only. 4 Some respondents indicated more than 1 item.
} 
room by anyone else. Therefore, for purposes of the following question, that patient was considered by the writer to have gone to the emergency room alone.

How Many Persons Went to the Emergency Room With the Patient

Forty-two $(72 \%)$ of the patients for whom schedules were received were accompanied to the emergency room by 1 or 2 people. Twelve (21\%) had no one with them; 2 (3\%) did not know how many people went with them; I patient had 3 persons; and, another had 4 people with him or her. No one was accompanied by 5 or more people.

Services Respondents Wanted Help Arranging

Patients (or their parents) were given a list of services a social worker can help arrange for people, and asked to check any they would have liked to talk with a social worker about when they (or their children) were in the emergency room. They were told to check as many as applied. Table XIX shows the responses to this question. Iypes of Problems Respondents Wanted Help With

Respondents were asked to indicate up to 3 problems they would have liked to have discussed with a social worker when they (or their children) were in the emergency room. Parents were told that the items indicated could be either problems for themselves or their child. 
TABLE XIX

WHAT RESPONDENTS WANTED HELP ARRANGING

\section{Type of Service}

Financial help

Emergency food

Place to live for a few days

Follow-up medical care

Immediate ride home or to another

agency, clinic or hospital

Ride for a medical appointment at another

time

Ride to a social service agency at another time Number of Persons Checking Item ( $N=58)$

Counseling

Other

None of the above

Do Not Know

Was not there 2

No Response
$2^{1}$

1

1

4

1

1

2

1

$42(72 \%)$

2

0

$7(12 \%)$

\footnotetext{
1 Some respondents indicated more than 1 item. 2 Listed on Parent Schedule only.
} 
Though they were asked to indicate relative importance of their responses, few respondents did so. Therefore, the researcher decided to give equal weight to all items which were indicated as problems, even in cases where the respondent prioritized his/her answer. By far the most common problem mentioned was worry about what effect the problem for which the patient came to the emergency room was going to have on his or her life (or, in the case of patients under 15, on the child's and/or the parent's life). Table XX lists all the alternatives which were given along with the number of responses for each.

Sex of Respondent who Wanted To Talk With a Social Worker

Some respondents checked "none of the above" and/or "do not know", or a combination of these two for both lists of items people might want to talk with a social worker about. In addition, some people checked "none" or "do not know" for one list, and did not respond to the other list. For purposes of this and the following tabulations, all of the above combinations of responses were grouped together as a "no services wanted" category. All respondents checking I or more items they would have liked to have talked with a social worker about were grouped together in a "wanted 
TABLE XX

TYPES OF PROBLEMS WITH WHICH

RESPONDENTS WANTED HELP

Iype of Problem

Number of Persons

Checking Item ( $N=58)$

Worry about effect of illness/

injury

$8^{1}$

Depressed - no suicide attempt

1

Suicide attempt

1

Family problems

1

Being all alone with no friends

1

Alcohol problem

Drug problem

0

Victim of rape/sexual abuse

0

Victim of non-sexual assault

0

Hurting, or fear of hurting, child/

children

Other

2

None of the above

$38(66 \%)$

Do Not know

$1(2 \%)$

Was Not There ${ }^{2}$

0

No Response

$6(10 \%)$

1 Some respondents indicated more than I item.

2 Listed on Parent Schedule only. 
services" category. Persons not responding to either list were put into the "no response" group. Table XXI shows the distribution of these groups by the sex of the respondent.

Who Wanted Services Compared to who Would Have Been Referred

Table XXII shows how many out of each of the groups described above would have been referred to a social worker by the nursing staff, as indicated in the schedules completed by the nurses.

Of the 16 patients whom the nurses would have referred to a social worker, only $\sigma(38 \%)$ returned schedules to the researcher. These numbers are so small, generalizations cannot be made about the amount of agreement between patients whom the staff would refer to a social worker, and the nursing staff, regarding the need for social work intervention.

Of those who returned schedules, 13 (22\%) would have liked to have talked to a social worker, but would not have been referred by the nurses. The reasons given by this group for wanting to talk with a social worker are listed in Table XXIII. Under "other", one person said "just to know someone cared enough to ask." The second person wanted more information on her child's illness and recovery. 


\section{TABLE XXI}

\section{DESIRE TO TALK WITH A SOCIAL WORKER \\ BY SEX OF RESPONDENT}

Whether Wanted

Social Work Service

Sex of Respondent $(N=58)$

Male

Female

$\mathrm{N} \quad \% \quad \mathrm{~N} \quad \%$

Wanted Service

$9 \quad 33^{1}$

No service wanted

16

59

19

61

No response

2

7

3

10

TOTAL

27

99

31

100

1 Due to rounding error, percents do not add up to $100 \%$. 
TABLE XXII a

DESIRE TO TALK WITH A SOCIAL WORKER BY WHETHER WOULD HAVE BEEN REFERRED

TO ONE BY NURSING STAFF

Whether Wanted Social Work Service

Whether Staff Would Have Referred $(N=58)$

Would

Would Not

Wanted Service

3

50

13

25

No Service Wanted

3

50

34

65

No Response

0

0

5

10

TOTAL

6

100

52

100

Below is another way to look at this same data -...-

Whether Staff Would Have Referred

Would

Would Not

TOTAL
TABLE XXIIb

Whether Patient Wanted Social Work Service

Wanted Not Wanted No Response $\mathrm{N} \% \quad \mathrm{~N} \quad \% \quad \%$

$\begin{array}{llllll}3 & 19 & 3 & 8 & 0 & 0\end{array}$

$\begin{array}{llllll}13 & 81 & 34 & 92 & 5 & 100\end{array}$

$\begin{array}{llllll}16 & 100 & 37 & 100 & 5 & 100\end{array}$ 


\section{TABLE XXIII}

\section{SERVICES WANTED BY RESPONDENTS}

WHO WOULD NOT HAVE BEEN REFERRED

TO A SOCIAL WORKER

Item Indicated

Financial help

Emergency food

Place to live for a few days

Follow-up medical care

Counseling

Worried about effect of illness/injury

Suicide attempt

Family problems

Emotional problems

Being alone with no friends

Alcohol problem

Hurting, or fear of hurting child/children

other
Number of Respondents ( $N=13$ )

$1^{1}$

1

1

3

I

8

1

1

$I$

1

2

1

2

1 Some respondents indicated more than 1 item. 
Reqular Doctor or Clinic

Eleven (19\%) of the patients by or for whom schedules were returned did not go to a regular doctor or clinic for medical care. Forty-six (79\%) did have a regular physician or clinic, and 1 (2\%) did not respond to this question.

Who Completed Children's Schedules

Of the 15 schedules returned for patients under 15 years old, 14 were completed by the child's parent and 1 by the child's foster parent.

\section{Sex of Respondent}

Twenty-seven men and 31 women completed schedules. Of these, 3 men and 12 women were completing schedules for their child or foster child.

Respondent's Level of Formal Education

Table XXIV shows the amount of formal education completed by respondents. (Formal education was defined to include trade school). Fourteen (32\%) of the patients 15 and over did not complete 12 years of school, as compared to only $2(13 \%)$ of parents of patients under 15. Deleting the two patients over 15 but under 19 on the assumption 
TABLE XXIV

YEARS OF FORMAL EDUCATION

COMPLETED BY RESPONDENTS

Who Completed Schedule $(N=58)$

Parent of

Patient 15+ Patient under 15

Number of Years

N $\quad \% \quad \underline{N}$

8 or less

$16^{1}$

0

$9-11$

7

16

13

12

13

30

47

$13-15$

11

26

13

$16-18$

4

9

20

No Response

1

2

1

7

TOTAL

43

99

15

100

1 Due to rounding error, percents do not add up to $100 \%$. 
they are too young to have been able to complete high school still leaves $12(29 \%)$ adult patients with less than 12 years of school as compared to 2 (13\%) parents of child patients.

\section{Maritel Status of Respondents}

As Table XXV shows, the marital status of parents of child patients is extremely similar to that of patients 15 years and older. Patients 15 and older have a slightly higher rate of single persons, but the reader should rememberthat this group includes 2 persons under 19.

Number of Persons Living in the Household

Patients (or their parents if under 15) were asked several questions about the composition of their household. The first question was asked only to introduce the topic, and was not tallied. All other responses are presented in Table XXVI. (Of the two respondents who were 17 and 18 years old, one indicated zero children in the household, and the other left questions about children blank. The wording of these items was such that siblings of these two respondents would not have been included unless over 18 years old).

Excluding those who had none, the average number of children living at least $\frac{1}{2}$ the time with a respondent was 


\section{TABLE XXV \\ MARITAL STATUS OF RESPONDENTS}

Marital Status

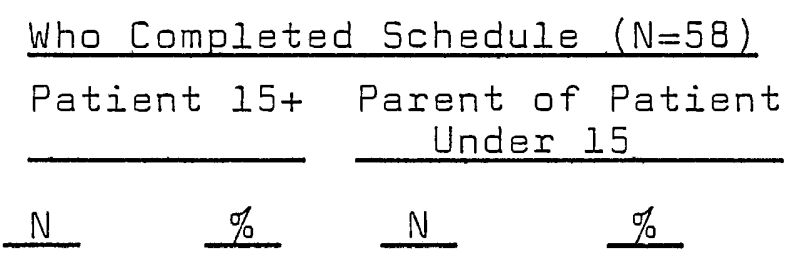

Single

12

28

3

20

Married

22

51

8

53

Separated

0

0

1

7

Divorced

5

12

2

13

Widowed

4

9

0

D

No Response

0

0

I

7

TOTAL

43

100

15

100 
TABLE XXVI

NUMBER OF PEOPLE LIVING WITH RESPONDENT

Number of

Persons

0

1

2

3

4

5

6

$\downarrow$

10

No Response

TOTAL
Who Is Living With Respondent $(N=58)$ Own or Other

Step-children Children Adults 19+

$\mathrm{N} \quad \% \quad \mathrm{~N} \quad \% \quad \mathrm{~N} \quad \%$

25

$43^{1} \quad 36$

$62 \quad 23$

$40^{1}$

7

12

$5 \quad 21$

36

7

12

0

$0 \quad 5$

9

5

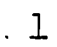

9

0

$0 \quad 0$

0

2

0

$0 \quad 0$

0

0

- 1

0

0

0

01

2

12

$21 \quad 18$

31

8

14

58

10158

100

0

0 (2) 
two and one-half. (Of those indicating other children living with them, all had children and/or step-children with them as well). Nearly half (43\%) of the respondents had no children in their household. Of the respondents, $23(40 \%)$ said they had no other adults living with them. However, out of these 23, 7 had stated that they were married (although "separated" had also been listed as an option). One explanation for this discrepancy may be that they misread the question.

Number of Times Patient Has Moved

Over half $(57 \%)$ of the patients had not moved in the previous 2 years. Only $6(10 \%)$ had moved 3 or more times during this time period. Table XXVII lists all responses to this item. 
TABLE XXVII

NUMBER OF TIMES PATIENT HAS

MOVED IN PREVIOUS TWO YEARS

Number of Moves

0

1

2 .

3

4

5

6

No Response

TOTAL
Number of Responses

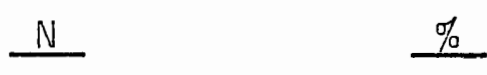

33

57

10

17

6

10

3

5

1

2

$I$

2

1

2

3

5

58

100 


\section{CHAPTER VI \\ CONCLUSIONS AND RECOMMENDATIONS}

\section{INTRODUCTION}

Some emergency room patients need assistance abtaining concrete, practical services such as food, shelter, or follow-up medical care. Dthers are in acute emotional distress. A social worker in the emergency room can help both of these groups of patients.

Maslow's (1948) hierarchy of needs and Caplan's (1974) Nutritional Model provide a theoretical framework for understanding the importance of helping people meet their basic personal needs; crisis theory provides a theoretical explanation of the efficiency and effectiveness of trained, skilled intervention with many people who are quite upset and anxious.

The purpose of this study is to explore the need for these services, among patients admitted to Providence Medical Center's emergency room at night and during the day shift on weekends. The study is also intended to provide demographic information about the emergency room patients admitted during these hours.

Descriptions of programs offering psychiatric emergency and/or crisis intervention services are available in the literature. Though they are usually very sketchy about 
what kinds of services they offer and to whom, those programs reviewed by this author do not seem to offer assistance to people who are in need of concrete services but who are not labeled "psychiatric" patients. (The term "psychiatric" is rarely defined). The literature contains very few descriptions of broader, social service programs. Similarly, studies are available in the literature of the demographic characteristics of patients served in a number of psychiatric programs in emergency rooms, but the author was not able to find any studies of patients assisted by social service programs in emergency rooms.

For this study at Providence Medical Center, a random sample of patients admitted to the emergency room at night and during the day shift on Saturday and Sunday was selected. A schedule was completed for each of these patients. In addition, the patients or their parents (if the patient was under 15) were mailed a schedule to be completed and returned to the researcher. Tabulations and analysis of the resulting data are presented in detail in Chapter $V$ of this report. There are three main limitations in generalizing the results of this study to all patients admitted to Providence Hospital's emergency room at night and on weekend day shifts. The first is that the sample, because it was drawn from a two-month period, may not be representative of patients admitted during an entire year. The second limitation is that 
$42 \%$ of the patients (or their parents, if under 15 ) did not return the schedule mailed to them. The third, and perhaps most serious limitation of this study, is that only 16 persons in the study would have been referred by the nursing staff to a social worker if one had been on duty in the emergency room. The smallness of this number means that generalizations about this group of patients must be made tentatively and be considered with caution.

In this chapter, the author will present the major findings of this study, conclusions and recommendations based on these, and recommendations for further study.

\section{MAJOR FINDINGS}

\section{Need For Social Services}

Of the 104 patients in the sample, the nursing staff would have referred $16(15 \%)$ to a social worker if one had been on duty in the emergency room. Of the 58 patients responding, $16(27 \%)$ stated they would have liked to have talked with a social worker when they were in the emergency room. Three of these (5\%) would have been referred by the nursing staff.

The reasons given most frequently by the nursing staff for referring a patient were: family and personal problems; problems (practical and/or emotional) related to the 
patient's illness or injury; a need by the staff for a psychosocial evaluation; and a belief that the patient needed services, but the staff did not know what type or for what problem(s).

By far the most common reason given by patients (or parents of patients under 15) who said they would have liked to have talked with a social worker was for assistance with problems (practical and/or emotional) related to the injury or illness for which the patient was in the emergency room.

When Patients Were Admitted

Of the 16 patients who would have been referred by the staff to a social worker, 9 were admitted at night and 7 during a weekend day shift. Since a $50 \%$ sample was taken at night and a $25 \%$ sample of the day shift, it is possible to use these figures to estimate that 1.5 patients per night shift and 4.67 per weekend day shift would be referred to a social worker.

Of the 7 patients admitted during a day shift who would have been referred, 5 were admitted on a Sunday. This information makes it possible to roughly estimate that 6.67 persons would be referred to a social worker on a Sunday day shift, compared to about 2.67 on a Saturday.

All but one of the patients who would have been referred to a social worker on a weekend day shift were admitted after 
10:00 a.m. Six of the nine patients admitted at night who would have been referred to a social worker were seen in the first half of the week (Sunday-Wednesday). Based on these figures, an estimated 2 patients per night would be referred to a social worker during this first part of the week, compared to about 1 per night for the last part of the week (Thursday-Saturday).

Of the 9 patients who would have been referred from the night shift, 6 were admitted between Il:00 p.m. and $3: 00 \mathrm{a} \cdot \mathrm{m}$.

Patients' Emergency Room Experience

Of the 58 persons for whom schedules were received, $12(21 \%)$ came to the emergency room by themselves. Fortytwo $(72 \%)$ were accompanied by 1 or 2 persons, usually a spouse (or person in a similar relationship) and/or a parent or step-parent.

Fifty-four of the 58 persons responding (93\%) reported being very or mostly satisfied with the medical care they (or their child) received and with the way they were treated by the hospital staff.

Forty-five of the 58 persons responding (78\%) remembered waiting 30 minutes or less before seeing a doctor. Of the 16 patients who would have been referred to a social worker if one had been on duty, 2 were admitted to the hospital, and services were arranged within a few hours 
for two others. The remaining 12 (75\% of those who would have been referred) were discharged from the emergency room without receiving any social services or referrals to community resources.

\section{Demographic Characteristics of Patients}

Of the 104 patients in the sample, 17 (16\%) were under 10 years old. None of these would have been referred to a social worker. Five patients ( $5 \%$ of the total) were 60 years old or more, of whom one would have been referred. Fifty-eight patients ( $56 \%$ of the total sample) were under 30. Half (8) of those who would have been referred were between 20 and 40 years old. Thirty-two of the 88 persons (29\%) who would not have been referred were in this age group.

Excluding all patients under 19, 10 of the $14(71 \%)$ who would have been referred to a social worker were not married. This compares to 30 of the $63(48 \%)$ patients 19 and older who would not have been referred.

of the 16 patients (or their parents, if the patient was under 19) who would have been referred to a social worker, 8 (50\%) were unemployed and either had no spouse or had a spouse who was also not employed. This compares to 32 of the $88(36 \%)$ who would not have been referred. Eight of the $16(50 \%)$ patients who would have been referred had no insurance or were covered by a plan for 
low-income people. Only 26\% (23 of 88) of those who would not have been referred fell into this group.

Of the 41 patients 19 and older who returned schedules, $12(29 \%)$ had not completed high school. Only 2 of the 15 (13\%) parents of patients under 15 who returned schedules had not finished high school.

Eleven ( $19 \%)$ of the patients for whom schedules were returned did not go to a regular doctor or clinic for medical caré.

Of the 58 patients for whom schedules were received, $33(57 \%)$ had not moved in the previous two years. Only 10\% ( 6 of 58) had moved 3 or more times in this period. Of the 16 persons who would have been referred to a social worker by the nursing staff, 11 (70\%) lived in Providence's primary catchment area. Three (16\%) of those who would have been referred did not live in either the primary or the secondary catchment area. These figures compare with $71(81 \%)$ and $7(8 \%)$, respectively, of the 88 patients who would not have been referred.

\section{CONCLUSIONS}

Emergency room patients admitted at night and on weekend day shifts do have unmet social service needs. Though the nursing staff would refer about $15 \%$ of the patients 
to a social worker if one were available, these patients are usually discharged without receiving any social service assistance or referrals. In addition, when asked, patients report social service needs of which the staff are unaware. When asked if they would like to receive certain services, it is common for people to indicate needs which they might not otherwise mention. Emergency room patients may not mention certain social service needs that they have unless specifically asked because the person has not yet been able to put the problem and/or its solution into words, the problem is not very pressing, or the patient is not aware that it is appropriate and/or of any use to mention these problems to the emergency room staff. Therefore, though asking patients if they would like certain services may lead to more requests than would spontaneously arise, it doesn't mean that these requests are not "valid" or important. Because the number of patients in this study who would have been referred to a social worker was quite small, only very tentative conclusions can be drawn about them. However, it appears from the data that (of the hours studied) the four time periods during which it would be most efficient to hire a social worker are: Sunday, from 10:00 a.m. to 3:00 p.m.; Saturday, from 10:00 a.m. to 3:00 p.m.; Sunday through Wednesday, from Il:00 p.m. to 3:00 a.m.; and Thursday through Saturday, from 11:00 p.m. to 3:00 a.m. The pro- 
jected workload would be highest on Sunday day shift, lowest on Thursday through Saturday night shift, and about the same during the other two time periods.

Because of the types of social service problems commonly mentioned by the staff and by patients, any person assigned to meet these needs will have to be familiar with crisis intervention techniques, common emotional reactions to illness and injuries, and use of community resources (especially for follow-up medical care).

Though the small number of patients makes a definite conclusion impossible, the data indicates that patients whom the staff recognize as needing social services have a higher probability than other patients of being poor and of being unmarried. It may be that, compared to other patients, these patients have fewer financial and personal recources to utilize in meeting their needs.

\section{RECOMMENDATIONS}

1) A person whose primary responsibility is to meet patients' social service needs should be on duty in the emergency room from 10:00 a.m. to 3:00 p.m. on weekends, and from 1l:00 p.m. to 3:00 a.m. seven nights a week. Priority should be given to weekend day shifts, followed by Sunday-Wednesday nights. Careful data should be kept so 
that these priorities can be re-evaluated as information is collected on a larger sample than was possible in this study.

2) The person(s) assigned to meet the social service needs of emergency room patients should be skilled at recognizing and dealing with emotional reactions to injuries and illness, providing crisis intervention for personal and family problems, and helping people utilize the local community resources. This person should also be able, through formal and informal means, to teach the rest of the emergency room staff how to best utilize his/her skills.

3) Because patients are not always able to spontaneously verbalize social service needs, the services this person can provide should be explained to patients (and their families), who then should be asked if they want to talk with him/her.

4) There are two groups who could probably fill a position of this type. Dne option would be to hire a medical social worker with experience in evaluation of and crisis intervention with patients with personal and family problems. Another option would be to hire a psychiatric nurse with a lot of medical experience and a background in public health care work. If a psychiatric nurse were hired, administra- 
tive guidelines would have to be written and enforced to ensure that she/he, though able to assist with medical procedures when appropriate, remained available to meet her or his primary responsibility of social service assistance to patients.

5) If it is not possible to increase social service coverage in the emergency room, the nursing staff should be helped to deal more effectively with these needs. One way to do this is to make referral sources for the most common problems patients present more readily available to them. This should include the name, address, phone number, hours available, and who is eligible for each agency listed, arranged by what services they provide. These could be on a small rolodex and/or on sheets of paper which could be given to patients. The three most important areas to include are probably low-cost medical care, immediate crisis intervention, and on-going counseling.

Giving the nursing staff more training in recognizing and responding to the emotional aspects of a person's illness or injury, and in dealing with psychiatric patients, may also help them meet patients' needs more effectively. It must be recognized, however, that lack of time, rather than lack of training, is often the problem.

6) The large number of patients under 10 years old underlines the importance of having pediatric services avail- 
able to the emergency room.

7) A final recommendation is that the emergency department and the social service department explore the possibility of emergency room patients admitted when no social service assistance is available being referred to the social service department for follow-up care. This could involve an appointment with or a phone call from the social service department during their regular working hours.

\section{RECOMMENDATIONS FOR FURTHER STUDY}

The first recommendation for further study is for a larger study of the time and day of admission of patients who would be referred to a social worker and who would like to talk with one than was possible in this research project. The study should include information about patients arriving during hours a social worker is presently on duty in the emergency room, as well as the hours there is no social worker available. The information gathered in such a study could be used to determine whether there are time periods not presently being served which have a greater need for social service coverage than some of the hours a social worker is presently on duty. If so, available social service coverage could be redirected to the periods of greatest need. A second recommendation is to study the social service needs of family members who come to the emergency room with patients. 
A third area recommended for study is a comparison of the number of patients referred to a social worker when one is on call to the emergency room with the number who would be referred if the social worker were present in the emergency room. Both groups could then be compared with the number of patients who, when asked, indicate social service needs. 


\section{A SELECTED BIBLIOGRAPHY}

Aguilera, D.C., and Messick, J.M., Crisis Intervention: Theory and Methodology. 5t. Louis: The C.V. Mosby Company, 1978.

Amdur, M.A., Alcohol-related problems in a general hospital emergency room. Illinois Medical Journal, $148(5): 509-510,1975$.

Amdur, M.A., and Tuder, E.N., Psychiatry in a general hospital emergency room. Illinois Medical Journal, $147(1): 39-41+, 1975 a$.

Amdur, M.A., and Tuder, E.N., Observations on psychiatric consultation in emergency room settings. Psychosomatics, $16(2): 73-76,1975 b$.

Atkins, R.W., Psychiatric emergency service: Implications for the patient, the physician, the family, the hospital and the community, Archives of General Psychiatry, 17(2): 176-182, 1967.

Atkinson, R.M., Importance of alcohol and drug abuse in psychiatric emergencies. California Medicine, 118

(4): $1-4,1973$.

Bartolucci, G., and Drayer, C.S., An overview of crisis intervention in the emergency rooms of general hospitals. American Journal of Psychiatry, 130(9): 953$960,1973$.

Beigel, A., The treatment team: Paramedics in emergency mental health services. Medical Insight, $4(12)$ : 30-35, 1972 .

Bennett, M.J., The social worker's role. Hospitals, 47 (10): $111-114+, 1973$.

Bellack, L.; Prola, M.; Meyer, E.J.; and Zunkerman, M., Psychiatry in the medical-surgical emergency clinic. Archives of General Psychiatry, 10(3): 267-269, 1964 .

Bellack, C., and 5mall, L., Emergency psychotherapy and brief psychotherapy. New York: Grune and Stratton, Inc., 1965 . 
Bergman, A.S., Emergency room: A role for social workers. Health and Social Work, I(I): 32-44, 1976.

Blais, A., and George, J., Psychiatric emergencies in a general hospital outpatient department. Canadian Psychiatric Association Journal, $14(2): 123-133,1969$.

Blane, H.T.; Muller, J.J.; and Chafetz, M.E., Acute psychiatric services in the general hospital: II. Current status of emergency psychiatric services. American Journal of Psychiatry, 124(4): 37-45, 1967 (Supplement).

Bloom, B.L., Definitional aspects of the crisis concept. In Parad, H.J. (Ed.), Crisis Intervention: Selected Readings. New York: Family Service Organization of America, 1965, pp. 303-311.

Bogard, H.M., Follow-up study of suicidal patients seen in emergency room consultations. American Journal of Psychiatry, 126 (7): 1017-1020, 1970.

Brockopp, G., Crisis intervention: Theory process and practice. In Lester, D., and Brockopp, G. (eds.) Crisis Intervention and Counseling by Telephone. Springfield, Illinois: Charles C. Thomas, 1973: 89-104.

Caplan, G., An approach to community mental health. New York: Grune and Stratton, Inc., 1961.

Caplan, G., Principles of preventive psychiatry. New York: Basic Books, Inc., 1964.

Caplan, G., Conceptual models in community mental health. In Caplan, G., Support systems and community mental health. New York: Behavioral Publications, 1974, PP. 245-255.

Chafetz, M.E.; Blane, H.T.; and Muller, J.J., Acute psychiatric services in the general hospital: I. Implications for psychiatry in emergency admissions. American Journal of Psychiatry, $123(6): 664-670,1966$.

Clark, E., Round-the-clock emergency psychiatric services. In Parad, H.J.(Ed.), Crisis Intervention: Selected Readings. New York: Family Service Organization of America, 1965, pp. 261-298. 
Coleman, J.V., and Errera, P., the general hospital emergency room and its psychiatric problems. American journal of Public Health, 53(8): 1294-1301, 1963.

Darbonne, A., Crisis: A review of theory, practice and research. Psychotherapy, Theory, Research and Practice, 4(2): 49-59, 1967.

Getz, W.L.; Altman, D.C.; Berleman, W.C.; and Allen, D.B., Paraprofessional crisis counseling in the emergency room. Health and Social Work, 2(2): , 1977.

Geta, W.L.; Fujita, B.N.; and Allen, D.B., The use of paraprofessionals in crisis intervention: Evaluation of an innovative program. American Journal of Community Psychalogy, $3(2): 135-144,1975$.

Glasscote, R.M.; Cumming, E.; Hammersley, D.W.; Ozarin, L.D.; and Smith, L.H., The psychiatric emergency: A study of patterns of service. (APA-NAMH) Joint Information Service, Washington, D.C., 1966.

Grumet, G.W., and Trachtman, D.L., Psychiatric social worker in the emergency department. Health and Social Work, l(3): 113-131, 1976 .

Hankoff, L.D.; Mischor, M.T.; Tomlinson, K.E.; and Joyce, S.A., A program of crisis intervention in the emergency medical setting. American Journal of Psychiatry, 131 (1): 47-50, 1974 .

Hersrud, M.L.; Kiser, K.; and Knox, C.M., Psychiatric emergency services in Oregon. Portland State University, School of Social Work, 1977, Unpublished Master's

Thesis.

Huffine, C.L., and Craig, T.J., Social factors in the utilization of an urban psychiatric emergency service. Archives of General Psychiatry, 30(2): 249-255, 1974.

Kassell, M.B., The acute psychiatric patient in the emergency room. Delaware Medical Journal, 47(5): 250-254, 1975.

Maslow, A.H., "Higher" and "Lower" Needs. The Journal of Psychology, 25: 433-436, 1948.

Muller, J.J.; Chafetz, M.E.; and Blane, H.T., Acute psychiatric services in the general hospital: III. statistical survey. American Journal of Psychiatry, $124(4)$ : 46-57, 1967 (Supplement). 
Nigro, S.A., A psychiatrist's experiences in general practice in a hospital emergency room. Journal of the American Medical Association, 214(9):1657-1660, 1970 .

O'Reagan, J.B., A psychiatric emergency service: A preliminary report. Canadian Medical Association Journal, 93 $(13): 691-695,1965$.

Parad, H.J., Preventive Casework: Problems and implications. In Parad, H.J. (Ed.) Crisis intervention: Selected Readings. New York: Family Service Organization of America, 1965, pp. 284-298.

Parad, H.J., and Caplan, G., A framework for studying families in crisis. In Parad, H.J. (Ed.), Crisis intervention: Selected readings. New York: Family Service Organization of America, 1965, pp. 53-72.

Parad, H.J.; and Resnick, H.L.P., A crisis intervention framework. In Parad, H.J., and Resnick, H.L.P., (Eds.) Emergency psychiatric care: The management of mental health crisis. Maryland: Charles Press Publishers, $1975,3-7$.

Rapoport, L., The state of crisis: Some theoreotical considerations. In Parad, H.J. (Ed.), Crisis intervention: Selected readings. New York: Family Service Organization of America, 1965, 22-31.

Schwartz, D.A.; Weiss, A.T.; and Miner, J.M., Community psychiatry and emergency service. American Jourmal of Psychiatry, $129(6): 710-715,1972$.

Sherber, J., and Russell, H.J., Emotional aspects of trauma need treatment, too. Modern Healthcare, 5(6): 37-39, 1976.

Shortliffe, E.C., The emergency room and the changing patterns of medical care. New England Journal of Medicine, 258 (I) : 20-25, 1958 .

Silbert, R., Psychiatric patients in the admitting emergency room. Archives of General Psychiatry, 11(1): 24-30, 1964 .

Spitz, L., The evolution of a psychiatric emergency crisis intervention service in a medical emergency room setting. Comprehensive Psychiatry, 17(1): 99-113, 1976 . 
Strinsky, [., Medical social work. Hospitals, 44(9): $58-60,1970$.

Tally, S.L., Patient's use of psychiatric services in a university hospital emergency room. University of Oregon, School of Nursing, 1977, Unpublished Master's Clinical Investigation.

Trier, T.R., and Levy, R.J., Emergent, urgent and elective admissions. Archives of General Psychiatry, 2l (4): $423-430,1969$.

Watson, J.D., Psychiatric problems in accident departments, Lancet, $1(7600): 877-879,1969$.

Zusman, J., The psychiatrist as a member of the emergency room team. American Journal of Psychiatry, 123 (11): $1394-1401,1967$. 
APPENDIX A

SCHEDULES AND COVER LETTERS 
ER SOCIAL SERVICE QUESTIONAIRE
1) Date
2) Time
and
3) Ago (in gears)
4)
Mele
5) Patient's chief complaint/s. (1.e.. what change in the patient's condition resulted in seeking medical attention now):
6) Staf's preilminary diagnosis:

Froblem appears to be: acute: chronic; not known

7) Check one or two or the following:

acute self-destructive behavior is present (intentional overdose, wrist slashing, etc.)

chronic self-destructive behavior appears to be present (drug or alcohol abuse, smoking. chronic flghting. rallure to take reasonable care of onsolng medical problem such as diabetes or hypertension or open wound, etc.)

no self destructive behavior appears to be present

not known if self-destructive behavior is present

9) If a social worker were present in the $\mathrm{ZR}$, would you refer this patient (or his parents/zuardians if patient is under 15) to the social worker?

- yes (Continue now at the top of the next page.)

no (Sk1p now to question 11 on the next page.)

PIEASE BE SURE THIS

QUESTICNAIRE IS STAMPED

WITH THIS PATIENT'S

ADDPESSCGRAPH PIATE

IN THE AREA TO THE BIGHT. 
9) Check any of the sollowing services for which you would refer this person (or parents if pt. Is under 15) to a soc1al worker. Check as many as apoly.

Einancial help

_emerzency food

Lmmediate temporary housing

arrange follow-up med1cal care

nursing home placement

counseling

transportati on now to home or an agency/1nstitution transportati on for medical care at another time

transportation to a social service agency at another t1me

would refer, but don't know what service/s needed.

other (please specify)

10) Please 1ndicate, in order of their importance, up to three (3) of the following problems for which you would refer this patient (or parents if pt. is under 15) to a social worker in the ER. Number from 1 to 3. w1th 1 being most important.

sulc1de attempt

denression (no sulcide attempt)

psychosis

ramt $1 y$ oroblems

other emotional problems

difficulty taking care of seif

soctal lsolation

alcohol problem

drug problem suspected/potential child abuse

rape/sexual abuse $\nabla 1$ ctim

non-sexual assault $\nabla$ ctim

"anxious parent" syndrome

anxlety about how 111ness/

injury may affect his iffe

need (by staff) for psychosoclal evaluation

abuse of $\mathrm{ER}$ services

other (spectey)

none of the above

11) Check the rinal disposition of this patient:

lert without $T x$

discharged, referred to social service agency

d1scharsed. referred to PMC soclal service dept.

discharged, no social service agency referral given

admitted to PMC:
ICU

CCU

other referred for admission to another hospltal (olease name ):

DOA or died in ER

other (specify)

unkmown 


\section{INPORMATION FROM ADMISSION SLIP}

PLEASE PILL OUT IF YOU HAVE TIME

A. Address :

\section{c1ty}

3. Marital status: state

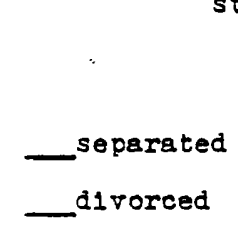

\section{1p}

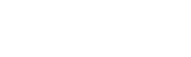

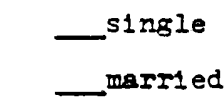
_single
- —married
_separated
_w1dowed

C. Occupation (parent's occupetion 1518 or under):

- housewlfe
student
unemployed
ret1red
disabled/hand1 capped
_other/employed

D. Is spouse employed? (spouse of above parent 1 pt. is 18 or under):

-yes _no not applicable n _ _ unknown

E. Insurance coverage:

Cascade
Portland Metro Health
OPS/Blue Shield
Providence CPC
welfare/medicald

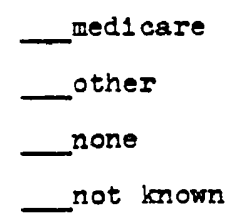

E-2. If Insurance is Cascade, Portland Ketro Health, OPS, or Providence OPC, Indicate group and pollcy number:

F. Source of Insurance:

INPORMATION FROM ADMISSION SIIP

PLEASE FILI OUT IF YOU GAVE TIME 
1) How satisfied were you with the quality of medical care you received in the Emergency Room?

not at all satisfied
somewhat satisfied
mostly satisfied
very satisfied
no opinion

2) How satisfied were you with the way you were treated by the hospital staff?

not at all satisfied
somewhat satisfied
mostly satisfied
very satisfied
no opinion

3) About how long did you have to wa it from the time you arrived at the hospital

$$
\begin{aligned}
& \text { until you were seen by a doctor? } \\
& \text { less than } 15 \text { minutes } \\
& \text { about } 15-30 \text { minutes } \\
& \text { about } 30 \text { minutes - } 1 \text { hour } \\
& \text { about } 1-1 \frac{1}{2} \text { hours }
\end{aligned}
$$

4) Who went to the Emergency Room with you?

no one

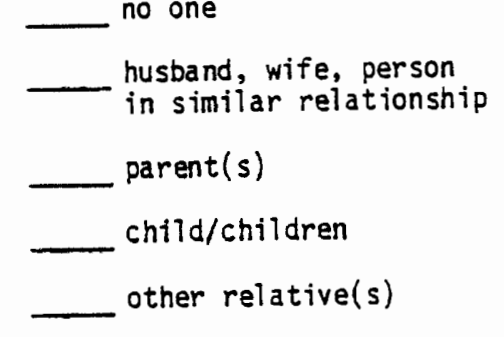

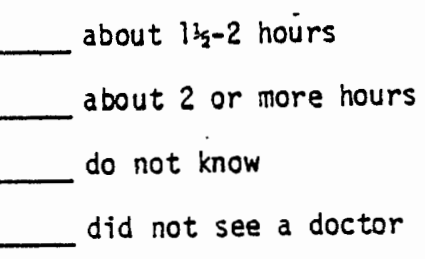

friend(s), neighbor $(s)$, acqua intance(s) person(s) from church or an agency ambulance drivers taxicab driver other do not know 
5) How many people went to the Emergency Room with you?

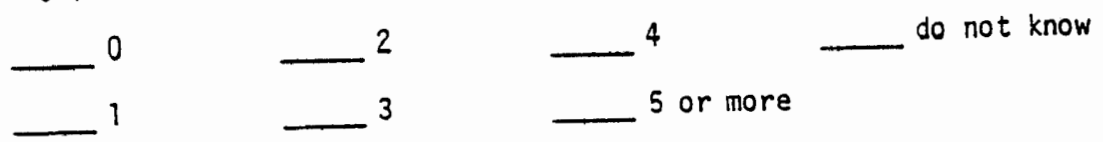

6) Here is a list of things a social worker can help arrange for people. Please check any you would have liked to talk with a social worker about when you were in the Emergency Room. Check as many as apply.

financial help
emergency food
a, place to live for a few days
follow-up medical care
an immediate ride home, or to
another agency, clinic, or
hospital
a ride for a medical appointment
at another time
a ride to a social service
agency at another time.

7) Here is a list of some other kinds of problems social workers can help people with. Please number, in the order of their importance, up to three (3) problens you would have liked to talk with a social worker about when you were in the Emergency Room. Number then from 1 to 3 , with 1 being most important.

worried about how your

illness/injury might affect your life being depressed (no suicide attempt made) suicide attempt family problems emotional problems being all alone with no friends alcohol problem drug problem being victim of rape/sexual abuse being victim of non-sexual assault hurting, or fear of hurting your child/children other (please explain) none of the above do not know 
8) Do you have a regular doctor or clinic you usually go to for medical care?

yes

9) How old are you?

10) What is your sex?

male female

11) How many years of schooling have you completed? (Grade school graduation = 8;

high school graduation $=12 ; 2$-year trade school after high school $=14$; college graduation $=16$; etc.) years of schooling

12) What is your marital status?

single
married

13) How many children and/or step-children who are 18 or younger do you have? 18 or younger

13-b) How many of these children live with you at least half of the time? children

13-c) How many other children 18 or younger (not including your own children or step-children) are usually living with you at any one time? children

14) How many people (not including yourself) who are 19 or older are usually living with you at any one time? people 19 and oider

15) How many times have you moved in the last two years? If you don't know, please guess.

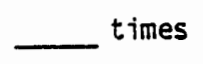


16) Are there any comments you would like to make?

THANK YOU VERY MUCH FOR TAKING TIME TO FILL OUT THIS QUESTIONNAIRE. YOUR ANSWERS WILL BE KEPT COMPLETELY CONFIDENTIAL, AND WILL BE USED TO HELP PROVIDENCE HOSPITAL IMPROVE ITS SERVICES TO YOU, YOUR FAMILY, AND OTHER PEOPLE IN OUR COMMUNITY. 
1) How satisfied were you with the quality of medical care this child received in the Emergency Room?

not at all satisfied
somewhat satisfied
mostly satisfied
mery satisfied
no opinion

2) How satisfied were you with the way you and the child were treated by the hospital staff?

not at all satisfied
somewhat satisfied
mostly satisfied
very satisfied
no opinion

3) About how long did you have to wait from the time you arrived at the hospital until this child was seen by a doctor?

less than 15 minutes
about $15-30$ minutes
about 30 minutes- 1 hour
about $1-1 \frac{1}{2}$ hours

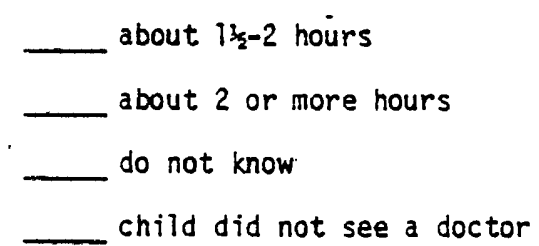

4) Who went to the Emergency Room with this child? (Check as many as apply; include yourself if you were there.)

_ no one
parent $(s)$, step-parent $(s)$
foster parent $(s)$
brother $(s)$, sister $(s)$
other relatives of the child

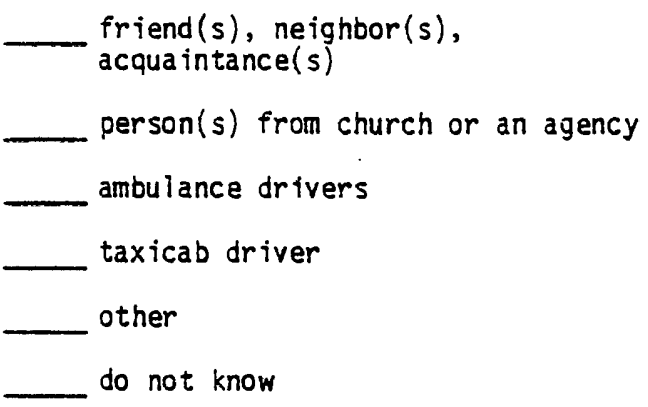


5) How many people went to the Emergency Room with this child? (Do not include the child who was the patient.)

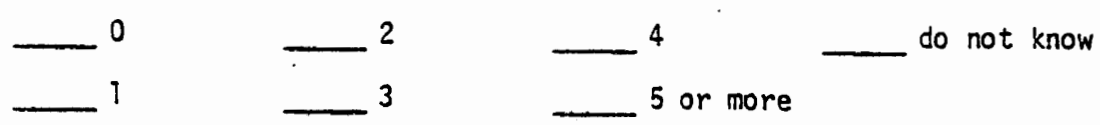

6) Here is a list of things a socjal worker can help arrange for people. Please check any you would have liked to talk with a social worker about when this child was in the Emergency Room.

financial help
emergency food
a place to live for a few days
follow-up medical care
an inmediate ride home, or to
another agency, clinic, or
hospital
a ride for a medical appointment
at another time
a ride to a social service
agency at another time

PLEASE GO TO NEXT PAGE 
7) Here is a list of some other kinds of problems social workers can help people with. Please number, in the order of their importance, up to three (3) problems you would have liked to talk with a social worker about when this child was in the Emergency Room. Number them from 1 to 3 , with 1 being most important. (These may be problems either for yourself or for the child.)

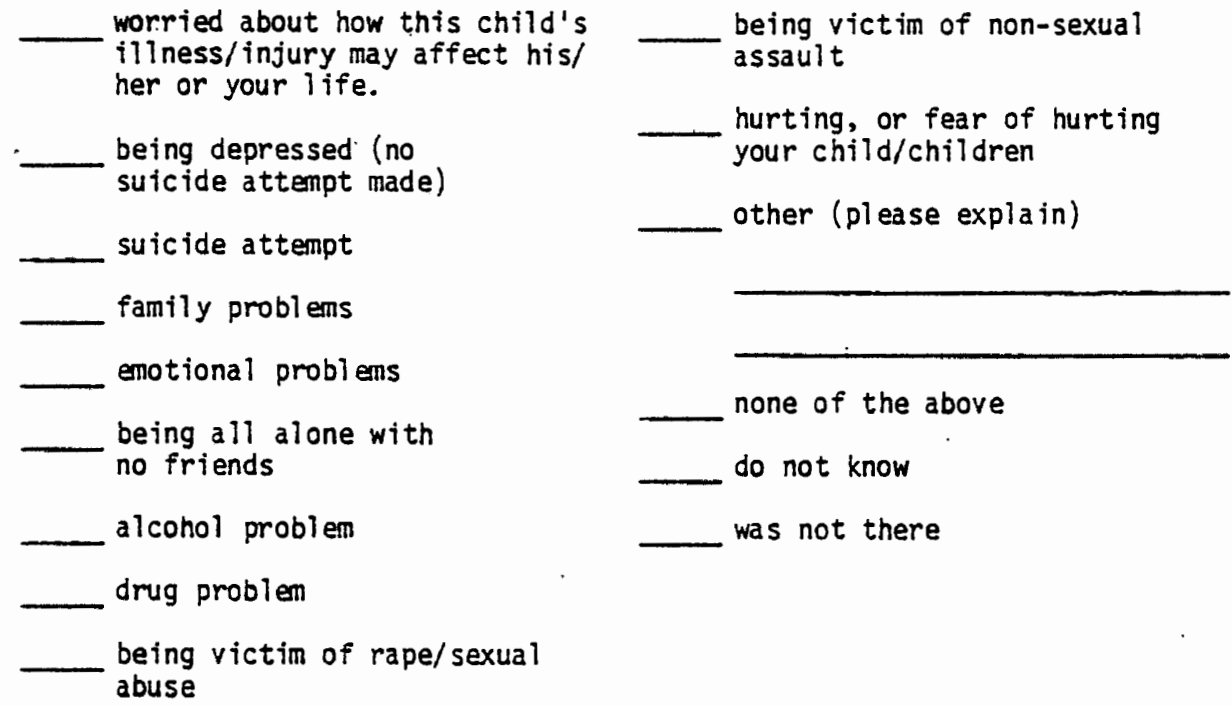

8) Does this child have a regular doctor or el inic he/she goes to for medical care? yes no

9) Are you this child's:

parent step parent foster parent

10) How old are you? years

11) What is your sex? male agency or group home worker other (specify) 
12) How many years of schooling have you completed? (Grade school graduation = 8; high school graduation $=12 ; 2$-year trade school after high school $=14$; college graduation $=16$; etc.) years of schooling

13) What is your marital status?

— $\begin{gathered}\text { single } \\ \text { married }\end{gathered}$ separated divorced $\quad$ widowed

14) How many children and/or step-children who are 18 or younger do you have? 18 or younger

14-b) How many of these children live with you at least half of the time? children

14-c) How many other children 18 or younger (not including your children or step-children) are usually living with you at any one time? children

15) How many people (not including yourself) who are 19 or older are usually living with you at any one time? people 19 and older

16) How many times has the child who was seen in the Emergency Room moved in the last two years? If you don't know, please guess. times

17) Are there any comments you would like to make?

THANK YOU VERY MUCH FOR TAKING TIME TO FILL OUT THIS QUESTIONNAIRE. YOUR ANSWERS WILL BE XEPT COMPLETELY CONFIDENTIAL, AND WILL BE USED TO HELP PROVIDENCE HOSP ITAL IMPROVE ITS SERVICES TO YOU, YOUR FAMILY, AND OTHER PEOPLE IN OUR COMMUNITY. 
Dear Parent or Guardian of

Will you help the staff of Providence Hospital improve their service to you, your family, and others in the Portland area? I and the staff of Providence's Emergency Room would greatly appreciate your taking a few minutes to fill out this questionnaire about your child's recent visit to the Emergency Room.

I am a graduate student in social work at Portland State University. I am doing a research project with Providence Hospital to learn more about the people who use the Emergency Room. The staff in the Emergency Room will then use this information to try to improve the help they give patients and their families.

Your child is one of the people chosen at random from those persons who visited the emergency room on Any information you give will be kept completely confidential. No names will ever appear in any report about this study. No facts will be given about any individual person; information will be reported only for groups of people (for example, "32 of the men in the study were 50 years or older"). No one at Providence will ever see your questionnaire; it will be destroyed by Apri1 30, 1978.

If you did not go to the Emergency Room with this child, it would be most helpful to have the person who did go with him/her fill out the questionnaire. If that is not possibie or would be hard to arrange, please fill out the form yourself the information you give will be very useful even if you were not at the hospital.

If you have any questions about this study, please feel free to call myself (228-5576) or Dr. Joseph Vander Veer, Director of Emergency Services at Providence Hospital (234-8211, ext. 477).

If you would like to receive a summary of the results of this study, write your name and address on the enclosed postcard and mail it to me at:

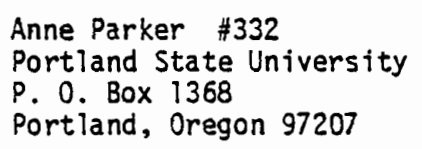

Thank you for taking the time to read this letter, and for cooperating to help us to better understand and meet the needs of our community.

Sincereily, 
Dear

Will you help the staff of Providence Hospital improve the ir service to you, your family, and others in the Portland area? I and the staff of Providence's Emergency Room would greatly appreciate your taking a few minutes to fill out this questionnaire about your recent visit to the Emergency Room.

I am a graduate student in social work at Portland State University. I am doing a research project with Providence Hospital to learn more about the people who use the Emergency Room. The staff in the Emergency Room will then use this information to try to improve the help they give patients and their families.

You are one of the people chosen at random from those persons who visited the emergency room on - Any information you give will be kept completely confidential. Your name will never appear in any report about this study. No facts will be given about any individual person; information will be reported only for groups of people (for example, "32 of the men in the study were 50 years ald or older"). No one at Providence will ever see your questionnaire; it will be destroyed by Apri1 30, 1978.

If you have any questions about this study, please feel free to call myseif (228-5576) or Dr. Joseph Vander Veer, Director of Emergency Services at Providence Hospital (234-8211, ext. 477).

If you would like to receive a sumary of the results of this study, write your name and address on the enclosed postcard and mail it to me at:

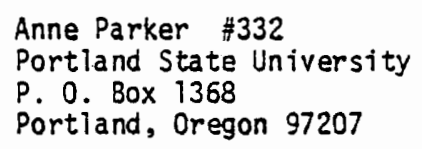

Thank you for taking the time to read this letter, and for cooperating to help us to better understand and meet the needs of our cormunity.

$$
\text { sincerely, }
$$

Anne Parker 
As part of a study I am doing with Providence Hospital's Emergency Room I recently mailed you a questionnaire. In case you never received it, or have misplaced it, I am including with this letter another copy of the form and of the letter which explains the study I am doing.

I would very much appreciate you taking a few minutes to read the letter and $f i 11$ out the questionnaire. Your answers will be helpful in Providence Hospital.'s efforts to improve the care they give people who use their emergency room. Any information you give will be kept completely confidential.

If you have already returned the questionnaire I sent you earlier, you do not need to fill this one out.

Thank you for your help.

Sincerely,

Anne Parker 
APPENDIX B

MAP OF CATCHMENT AREAS 
MAP OF CATCHMENT AREAS

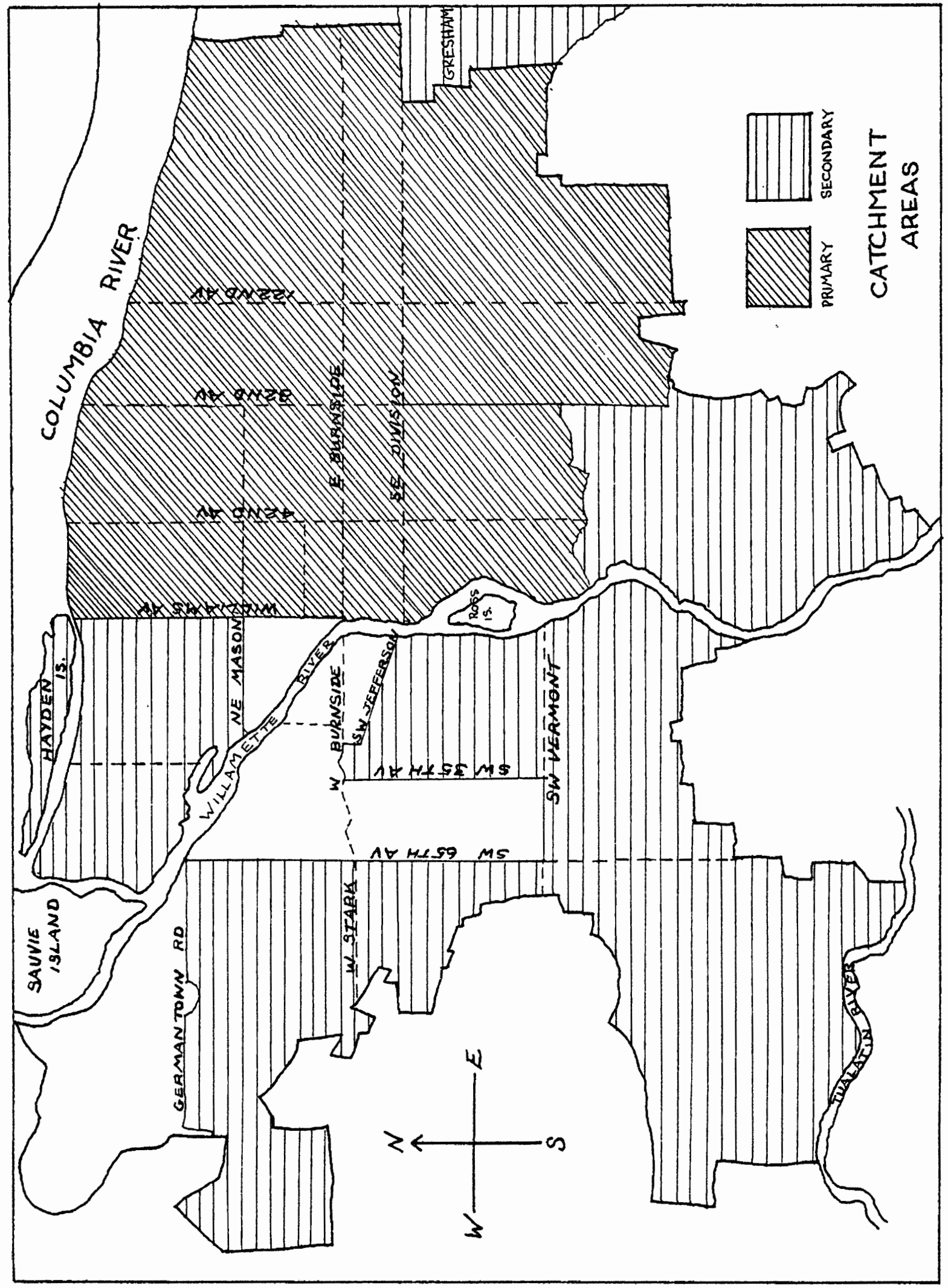

